\title{
WHEN THE GREAT EQUALIZER SHUTS DOWN: SCHOOLS, PEERS, AND PARENTS IN PANDEMIC TIMES
}

\author{
Francesco Agostinelli \\ Matthias Doepke \\ Giuseppe Sorrenti \\ Fabrizio Zilibotti
}

Working Paper 28264

http://www.nber.org/papers/w28264

\author{
NATIONAL BUREAU OF ECONOMIC RESEARCH \\ 1050 Massachusetts Avenue \\ Cambridge, MA 02138 \\ December 2020
}

We thank seminar participants at the CEPR Webinar on Gender Economics, Mannheim University, and Penn State for helpful suggestions. Special thanks to Abi Adams-Prassl, Teodora Boneva, Marta Golin, and Christopher Rauh for sharing unpublished results from the Covid Inequality Project with us. We also thank Shengqi Ni for research assistance. Doepke and Zilibotti acknowledge support from the NSF Grant \#1949228 "Parenting Styles within and across Neighborhoods." The views expressed herein are those of the authors and do not necessarily reflect the views of the National Bureau of Economic Research.

NBER working papers are circulated for discussion and comment purposes. They have not been peer-reviewed or been subject to the review by the NBER Board of Directors that accompanies official NBER publications.

(C) 2020 by Francesco Agostinelli, Matthias Doepke, Giuseppe Sorrenti, and Fabrizio Zilibotti. All rights reserved. Short sections of text, not to exceed two paragraphs, may be quoted without explicit permission provided that full credit, including $\odot$ notice, is given to the source. 
When the Great Equalizer Shuts Down: Schools, Peers, and Parents in Pandemic Times Francesco Agostinelli, Matthias Doepke, Giuseppe Sorrenti, and Fabrizio Zilibotti NBER Working Paper No. 28264

December 2020

JEL No. I24,J13,J24,R20

\begin{abstract}
$\underline{\text { ABSTRACT }}$
What are the effects of school closures during the Covid-19 pandemic on children's education? Online education is an imperfect substitute for in-person learning, particularly for children from low-income families. Peer effects also change: schools allow children from different socioeconomic backgrounds to mix together, and this effect is lost when schools are closed. Another factor is the response of parents, some of whom compensate for the changed environment through their own efforts, while others are unable to do so. We examine the interaction of these factors with the aid of a structural model of skill formation. We find that school closures have a large and persistent effect on educational outcomes that is highly unequal. High school students from poor neighborhoods suffer a learning loss of 0.4 standard deviations, whereas children from rich neighborhoods remain unscathed. The channels operating through schools, peers, and parents all contribute to growing educational inequality during the pandemic.

Francesco Agostinelli

University of Pennsylvania

133 South 36th Street

Philadelphia, PA 19104

fagostin@upenn.edu

Matthias Doepke

Northwestern University

Department of Economics

2211 Campus Drive

Evanston, IL 60208

and NBER

doepke@northwestern.edu

Giuseppe Sorrenti

University of Amsterdam

Amsterdam School of Economics

Roetersstraat 11

1018 WB Amsterdam

The Netherlands

g.sorrenti@uva.nl

Fabrizio Zilibotti

Department of Economics

Yale University

28 Hillhouse Avenue

New Haven, CT 06520

and NBER

fabrizio.zilibotti@yale.edu
\end{abstract}


Education, then, beyond all other divides of human origin, is a great equalizer of conditions of men - the balance wheel of the social machinery.

—Horace Mann, 1848

\section{Introduction}

Of the many facets of the Covid-19 pandemic, the impact on children's education stands out as having particularly long-lasting consequences. Schools were closed for months in most countries, and early evidence suggests that online education that was offered as an alternative is a poor substitute. School closures threaten to widen inequality not only across cohorts but also across socio-economic groups. For example, online education relies on access to technology like computers and fast internet that not all families can afford. Likewise, parents' ability to support their children's learning depends on their own knowledge and on whether they can work from home during the crisis. Because learning is a cumulative process, part of the effects of the disruption will persist until children reach adulthood, thereby affecting their future success in labor markets, family formation, and other dimensions of social life.

How should policy be designed to mitigate learning losses and their effects? The Covid-19 crisis is still ongoing and unlikely to be resolved for a number of months. During this time, policymakers must decide whether to continue school closures, open all schools, or follow a more flexible policy of partial openings. If partial openings are pursued, they must determine how to target openings. Another important question is whether additional programs should be offered after the pandemic subsides and which groups of students deserve special attention. Given that organizing such programs on a large scale requires planning and resources, decisions must be taken soon.

For answering these and other related questions, we need to understand both the size of the problem and the channels through which the crisis affects children. The fact that online learning is less effective than in-school learning is well recognized. But the accumulation of both cognitive and non-cognitive skills does not depend on schools alone. Especially for older children, peer interactions are another crucial ingredient, and school closures and lockdown measures during the 
pandemic drastically change children's social interactions and peer environment. The response of parents is no less important: they can complement education in school, replace some of the inputs usually provided by teachers, and influence their children in other ways such as through their choice of a parenting style. Parents' ability to do all of this interacts with their own exposure to the crisis, such as whether they lost their job or could work from home during lockdowns. In this paper, we provide a first assessment of how these channels interact during a pandemic. We focus on the impact on the education of students in high school, from grades 9 to 12 . We organize our analysis with a structural model of skill acquisition based on Agostinelli et al. (2020). The model captures how children's skill acquisition depends on educational inputs such as the quality of schools, parental inputs that include educational investments and parenting style, and on peer groups that are endogenously chosen. We use pre-crisis evidence from the Add Health data set to discipline the time-invariant parameters of the model.

We model the impact of the Covid-19 pandemic through a set of temporary changes in the economic environment. First, the switch to remote learning lowers the overall productivity of the learning technology. The size of the productivity loss is chosen to match evidence on lower test score growth during the current crisis. Second, there are changes to the peer environment: children may lose contact with some peers, and new peer connections are shaped by the peer environment in the neighborhood of residence rather than the school. We discipline this part of the model using evidence from Add Health on the impact of losing peer connections on learning, and on differences in the peer environment at the level of neighborhoods and schools (which draw students from multiple neighborhoods). Third, remote learning makes greater demands on parents, who have to supply some inputs usually provided by teachers and take a greater role on organizing, inciting, and supporting their children's learning. This aspect of the model is matched to empirical evidence on the increase in the time parents spend on helping their children with school during the current crisis. We also take into account that parents' ability to spend time helping their children depends on their own constraints, such as whether the parent is able to work from home during the pandemic. We use evidence on how the ability to work from 
home correlates with parental characteristics to quantify these constraints.

Our quantitative model is able to replicate the impact of the Covid-19 crisis on student's educational performance and on parents' time allocation. Our structural model implies that each channel of change to children's skill acquisition contributes to widening educational inequality during the crisis. Beyond the direct impact of the switch from in-person to virtual schooling, children from low-income families are also affected by a decline in positive peer spillovers, and parents in low-income families face greater challenges in supporting their children's learning, in large part because they are less likely to be able to work from home. In our baseline calibration, these effects combine to generate a skill loss relative to a counterfactual of no pandemic of 0.4 standard deviations for children from a census block at the 20th percentile of the income distribution, versus almost no losses at all for children from the richest neighborhoods. Learning gaps are reduced somewhat in subsequent years, but are still large at the end of high school, when less than half of the gap opened during the pandemic is closed.

We can then use the structure of the model to decompose how different channels working through schools, peers, and parents contribute to overall learning losses and to changes in educational inequality. While each channel makes a sizeable contribution, the peer effects channel turns out to be the most important: in a counterfactual that keeps the peer environment constant but introduces all other pandemic-induced changes, the change in educational inequality is reduced by more than 60 percent.

We also discuss policies that may be used to prevent some of the learning losses and widening educational inequality predicted by our structural model. Opening schools would be the obvious solution, but clearly educational benefits must be weighed against repercussions in terms of spreading of the pandemic. Still, the large detrimental effects on overall skill acquisition and inequality implied by our analysis can inform tradeoffs faced by policymakers, such as how much priority to give to opening schools relative to other sectors of the economy. Our results also highlight which groups of students would benefit most from restoring in-person schooling. Beyond students from low-income families in general, this also includes students who are already undergoing a change in the peer en- 
vironment, such as those who enter high school after having completed middle school, who are especially vulnerable to the detrimental effects of being separated from peers. Some of the impact of the pandemic on children's education could be mitigated by expanded in-school support once the pandemic is under control, for example by shortening the summer break in 2021 or offering targeted services to disadvantaged groups.

Our paper builds on three strands of the literature. The first is the economic literature on children's skill formation, including the contributions by Cunha, Heckman, and Schennach (2010), Del Boca, Flinn, and Wiswall (2014), Agostinelli and Wiswall (2016), and Attanasio et al. (2020) and recent work considering the role of parenting styles that is summarized by Doepke, Sorrenti, and Zilibotti (2019). The second related literature considers neighborhood effects for children's skill acquisition, such as Chetty, Hendren, and Katz (2016), Chetty and Hendren (2018a, 2018b), Eckert and Kleineberg (2019), and Fogli and Guerrieri (2018)..$^{1}$ Finally, our work is part of the emerging literature on the consequences of the Covid-19 pandemic for families and children. Our work relates in particular to Fuchs-Schündeln et al. (2020), who also use a structural model to examine the impact of pandemic-induced school closures on educational inequality. Their contribution is complementary to ours; Fuchs-Schündeln et al. (2020) examine on the macroeconomic angle and account for the economic impact of the crisis, government transfers, and different stages of education, whereas we focus on the interaction of influences of schools, peers, and parents at the high school stage and discipline the analysis using data on children's educational performance and parents' behavior during the crisis. Alon et al. (2020) also consider effects of school closures, but with a focus on implications for parents' labor supply rather than children's education. We link our work to additional empirical contributions specifically on the impact of the pandemic on children's education in Section 2 below.

In the next section, we provide descriptive evidence that sheds light on how a

\footnotetext{
${ }^{1}$ Within this literature, Calvó-Armengol, Patacchini, and Zenou (2009) consider the role of a child's position in her local friendship network (measured by the Katz-Bonacich centrality) on school performance. More recently, List, Momeni, and Zenou (2019) have documented large spillover effects (operating through children's social networks) of programs targeting disadvantaged children.
} 
pandemic changes children's education and peer environment. In Section 3, we present a structural model of skill acquisition, peer formation, and parenting that we will take to the data. In Section 4, we calibrate the model to match evidence on children's skill acquisition and on the changes brought about by the Covid-19 pandemic. In Section 5, we present our main results on how different changes during a pandemic affect children's overall learning and educational inequality. Section 6 discusses policy implications of our analysis, and Section 7 concludes.

\section{Empirical Evidence: How School Closures Affect Children's Education}

Our analysis focuses on three channels through which school closures affects child development and human capital formation. The first is the direct effect of suspending in-person teaching and replacing it with online instruction. The second is the change in the peer environment when children stop going to school, which includes the psychological impact of losing contact with some friends and a changed pool for making new connections. The third is the parents' response. Parents have to replace some of the inputs usually provided by professional teachers with their own efforts, subject to the constraints imposed by the requirements of their own work. We start our analysis by describing evidence that allows a first assessment of the importance of these channels.

Effect of School Closures in the United States. A benchmark to evaluate the direct effect of the interruption of in-person teaching is what happens during regular summer breaks. ${ }^{2}$ A RAND Corporation study from McCombs et al. (2014) uses results for standardized MAP tests to measure the extent of learning losses. They document a 4-point drop in the mathematics score on the RIT scale during each summer break, which compares with an 8-point gains that accrue from sixth to eighth grade during regular school years. In English, students gain five points during the school year and lose two points during summer. These figures suggest that a child who does not engage at all with learning activities during a school closure lasting three months could lose four points in math and two points in

\footnotetext{
${ }^{2}$ The discussion in this paragraph follows Doepke and Zilibotti (2020). For evidence on summer losses see also Downey, von Hippel, and Broh (2004).
} 
English. In comparison, a child who keeps on learning at the usual speed gains about 2.7 points in math (i.e., a third of the gain during an academic year) and 1.7 points in English during the same period. The achievement gap between these two scenarios is about seven points in math and four points in English. This is larger than the typical learning gain during a school year. Therefore, if some families can fully make up for the lack of in-person teaching while others make no remedy, a gap equivalent of more than an entire year of schooling can arise. ${ }^{3}$

Effect of School Closures: International Evidence. A number of studies provide first assessments of the effects of Covid-induced school closures in different countries. Maldonado and De Witte (2020) compares standardized test scores of Belgian students attending the last year of primary school who were affected by school closures (cohort of 2020) with those of previous cohorts. Students exposed to school closures experience a decrease in mathematics and language scores by 0.19 and 0.29 standard deviations, respectively. These are large effects. Moreover, school closures deepen existing inequality as children from more disadvantaged backgrounds experience larger learning losses. Engzell, Frey, and Verhagen (2020) find similar results in the Netherlands, a country with a relatively short 8-weeks lockdown and high degree of technological preparedness. Their difference-in-differences finds large learning losses, especially for students from less affluent families. ${ }^{4}$ In short, a variety of international studies point at large effects on learning of school closures.

Time Diaries. Time diaries for children's activities during the crisis also help us understand why the pandemic has unequal effects across the socio-economic ladder. The analysis of a sample of German parents in Grewenig et al. (2020) suggests that low-achieving students may suffer more from the lack of educator support during school closures. Compared to high achievers, these students appear to disproportionately replace learning time with less productive activities

\footnotetext{
${ }^{3}$ Kuhfeld et al. (2020a) reach similar conclusions based on the evidence about learning losses because of absenteeism, summer breaks, and weather-related school closures. Kuhfeld et al. (2020b) find smaller effects when comparing a cohort of student assessed in the fall 2019 with that of the cohort of students assessed in the fall 2020. However, the authors acknowledge that their preliminary results might severely underestimate the effect of the pandemic on students' achievements due to selective attrition in the studied sample.

${ }^{4}$ Di Pietro et al. (2020) provide an insightful report covering a few European countries.
} 
such as watching TV or playing computer games. Andrew et al. (2020) reach similar conclusion for a sample of English children.

Losing Contact with Friends. School closure also affects children's socialization with peers. A large literature in economics and developmental psychology documents large peer effects in education. ${ }^{5}$ To evaluate the effects of Covid on socialization, we consider the Add Health data set, which focuses on a representative sample of high school students in the United States. One aspect of the peer-interaction channel is that the forced separation from friends can have psychological effects that hinder the learning process. Detachment from close friends can be a source of stress and instability. In particular, we study how separations affect children's learning in normal (non-pandemic) times. In the Add Health data set, parents and children are interviewed twice over two different school years (Wave I and Wave II In-Home). When some children are not in the Wave II sample, although they were active respondents of the Wave I In-Home survey, we infer that they have left the school. We can then study the effect of a child leaving the school on the academic performance of their friends who continue in the school.

Table 1 provides regression results. For children moving from 8 th to 9 th grade, the loss of one friend is associated with a deterioration of more than 10 percent in growth in the grade point average (GPA). ${ }^{6}$ The result is robust to controlling for other determinants of school performance and for school fixed effects, and is larger for boys than for girls (see Table A-1 in the appendix). The negative effect is twice as large for children who lose two or more friends relative to those who lose only one friend. Table 2 shows the result of a specification where separation is interacted with the pre-separation GPA of the child. The negative effects are larger for low achievers. In other words, high achievers appear to be more resilient and cope better with losing contact with friends. Taking stock, there

\footnotetext{
${ }^{5}$ See, e.g., Durlauf and Ioannides (2010), Sacerdote (2011), and Epple and Romano (2011) for extensive reviews on the role of peer effects in education.

${ }^{6}$ The descriptive analysis in this section ignores important econometric issues in the study of peer effects. For instance, it is possible that a correlated shock hits the families of two friends, inducing one of them to move. This shock (e.g., a job loss) could have direct effects on the performance of the stayer. For this reason, we refrain from a strict causal interpretation. Note that we control for school fixed effects that reduces but does not eliminate these concerns.
} 
is evidence that forced separation from friends negatively affects children's academic performance, and that this impact is particularly large for children who are already struggling in school.

Interestingly, the effect of being separated from friends is small and statistically insignificant in higher grades beyond 9th grade (see Table A-2 in the appendix). One interpretation of this finding is that children may be especially vulnerable to changes in their peer environment when they are changing schools (i.e., entering high school in grade 9 after completing middle school). Older children who continue in the same school may have already established a stable group of friends in their new environment, so that losing one or two peers has less of an impact. This observation suggests that children who switch schools may be especially vulnerable during the pandemic. ${ }^{7}$

Changes in the Peer Environment. Beyond losing existing friends, the pandemic also changes children's ability to form new peer connections. Schoolmates who live far away may no longer be potential friends once children stop attending school in person. Instead, the peer interactions that are still possible happen at the level of the neighborhood. Even if children are able to make new connections, this distinction matters because the peer environment may differ at the level of the school and the neighborhood. To quantify these effects, we suppose here that when schools close down, children's peer environment is restricted to the neighborhood in which they live, which we assume to be the census block of their residence. The Add Health data allows us to infer the characteristics of census blocks where each child lives. ${ }^{8}$ While US school districts are characterized by a high degree of social sorting by international standards, the extent of socioeconomic segregation is even higher if children's peer interactions get confined to the block level. In other words, schools operate as an equalizer insofar as they mix children from different socio-economic backgrounds.

Figure 1 shows a bin scatter plot displaying the correlation between median fam-

\footnotetext{
${ }^{7}$ See Appendix Tables A-1 to A-5 for additional regression results on the effects of peer separation.

${ }^{8}$ The contextual data section in Add Health includes information matched from the 1990 US Census. We use median household income at the census block to characterize the neighborhood where children live.
} 


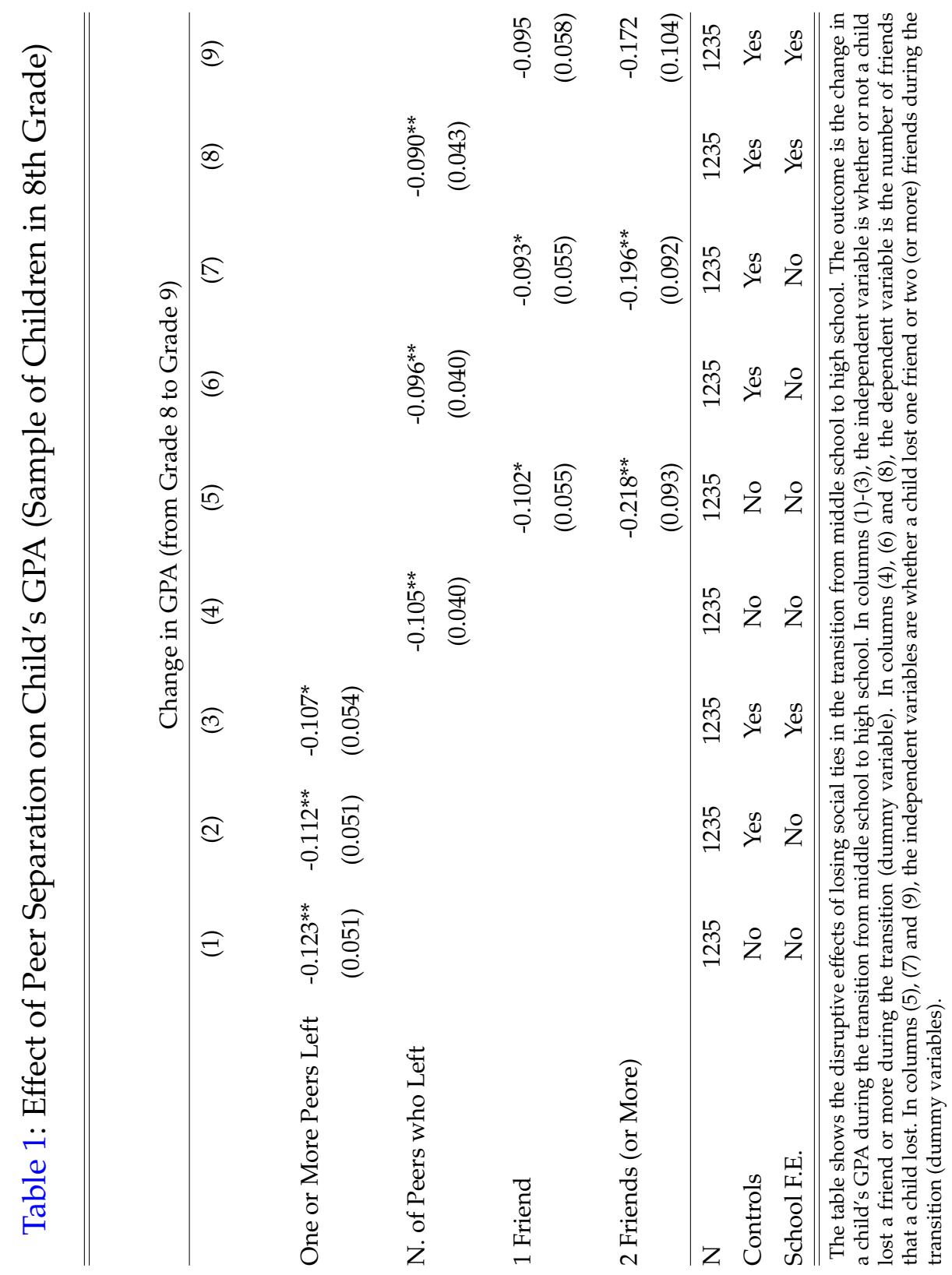


Table 2: Effect of Peer Separation on Child's GPA: Heterogeneity

Change in GPA (from Grade 8 to Grade 9)

(1)

(2)

(3)

N. of Peers who Left

$-0.314^{* *}$

$-0.268^{* *}$

$-0.576^{* *}$

$-0.540^{*}$

N. of Peers who Left $\times$ Child's GPA (t-1) $\quad 0.086^{* *} \quad 0.067^{*}$

$(0.040) \quad(0.040)$

N. of Peers who Left $\times$ Peers' GPA ( $t-1)$

$0.166^{*}$

0.155

$(0.093)$

$(0.098)$

\begin{tabular}{lcccc}
\hline $\mathrm{N}$ & 1235 & 1235 & 1223 & 1223 \\
Controls & Yes & Yes & Yes & Yes \\
School F.E. & No & Yes & No & Yes \\
\hline \hline
\end{tabular}

The table shows the heterogeneous disruptive effects of losing social ties in the transition from middle school to high school. The outcome is the change in a child's GPA during the transition from middle school to high school. In columns (1)-(2), we interact the number of friends that a child lost with the child's own GPA during 8th grade. In columns (3)-(4), we interact the number of friends that a child lost with the child's peer quality during 8 th grade.

ily income at the census block level and the average grade of children attending the same school (blue) or living in the same census block (red). As expected, the correlation is positive, namely, children living in richer blocks are exposed to academically stronger peers. The important observation is that the regression line is substantially steeper as we move from schools to blocks. For the children of poorer families, schools provide an opportunity to socialize with children from more privileged environments (relative to the block where they live). In contrast, the children of richer families meet children from less affluent families. Thus, the evidence on the peer environment channel adds to the overall theme that pandemic restrictions increase inequality in educational opportunities, here through the peer groups that children have access to. 
Figure 1: Peer Quality: School vs Neighborhood

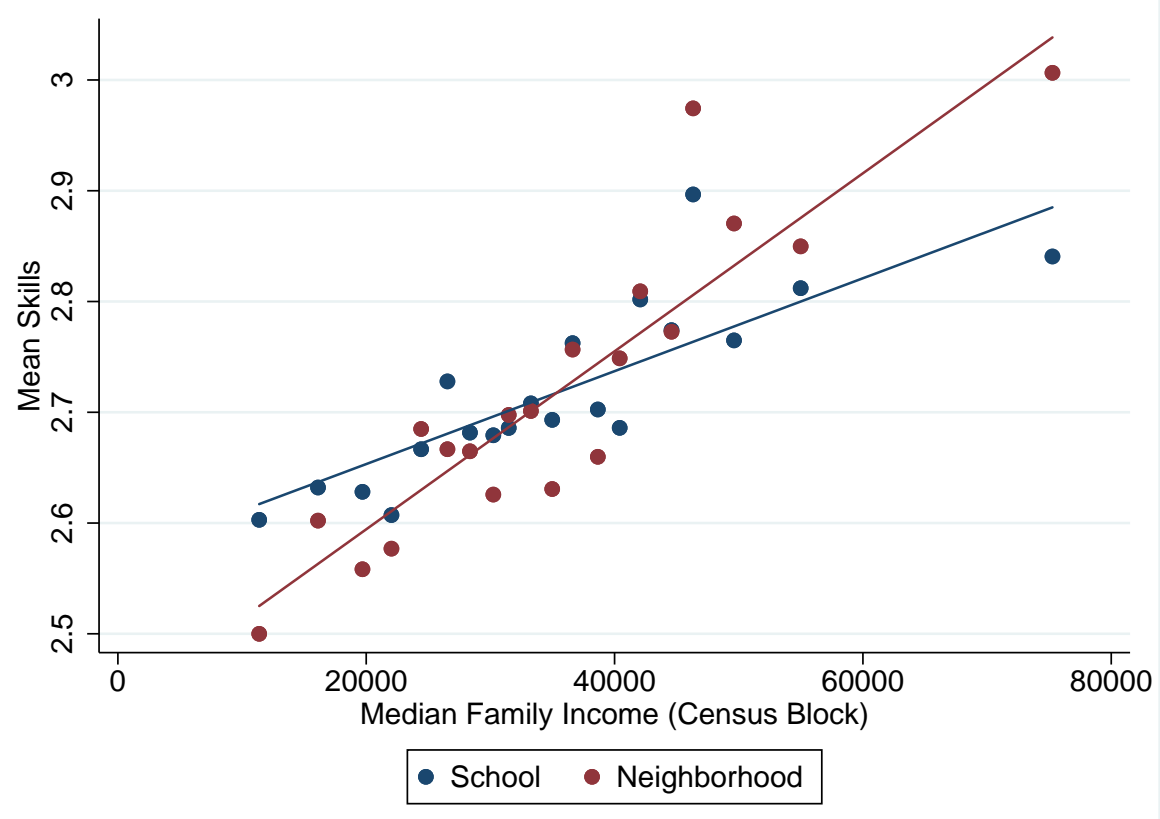

The figure shows the relationship (scatter plot) between peer quality and median family income at the census block level. The blue dots represent the predicted peer quality that children are exposed to at school by the median family income of the census block where children live. The red dots represent the peer quality composition of the census blocks where children live. Peer quality is measured by children's GPA.

Changes in Parenting: Knowledge and Time Constraints. Another channel through which a pandemic affects learning is through changes in parents' behavior and parental investment. Virtual schooling places new demands on parents, from making sure that children have access to the technology they need to replacing some of the tutoring, encouragement, and admonishment usually provided by teachers. Not all parents are equally able to provide these inputs. In some cases, knowledge might be a constraint, for example when helping children with homework in advanced high school math. Time constraints are likely to be even more important. Most parents have to earn a living in addition to being substitute teachers, which limits the inputs they can provide. These constraints are especially binding for single parents with limited resources, and single parenthood is more prevalent among parents with less education and lower earnings prospects. For parents who were employed during the crisis, a key issue was 
whether they could do their work from home, such as academics and other office workers working from their home office, or had to go to another workplace, such as most workers in manufacturing, supermarkets, and other retail outlets. Once again, the aspect of working from home introduces an element of inequality across the socio-economic ladder. Mongey, Pilossoph, and Weinberg (2020) show that workers with less income and education are more likely to be unable to work from home during the crisis than others. In our analysis below, we use survey evidence from Adams-Prassl et al. (2020a, 2020b) to quantify the extent to which the ability to work from home varies across the income scale.

Changes in Parenting Style. Beyond the the impact of knowledge and time constraints, parenting styles tend to adjust to changes in the peer environment. Here a relevant observation - which is the focus of our previous research in Agostinelli et al. (2020) - is that parents become more authoritarian when children are exposed to a more unequal environment. In particular, some parents actively discourage their children from interacting with lower-achieving peers, especially when their children are low achievers themselves. The evidence discussed above suggests that the peer environment deteriorates for poor families during the pandemic. Thus, we expect parents from a lower socio-economic background to turn more authoritarian during school closure periods. This has two effects. First, changes in parenting style makes it even harder for the most disadvantaged children to interact with stronger peers. Second, an authoritarian parenting style (albeit rational from the point of view of parents) has a negative direct effect on the process of skill formation and reduces educational achievement.

Agostinelli et al. (2020) zoom in on a narrower dimension of authoritarian parenting, namely, meddling with the choice of friends. ${ }^{9}$ Figure 2 reproduces Figure 1 in Agostinelli et al. (2020). It shows how authoritarian parenting varies across schools with different characteristics. The left panel displays a binned scatter plot of the relationship between median family income and the fraction of authoritarian parents at the school level, whereas the right panel shows the

\footnotetext{
${ }^{9} \mathrm{~A}$ parent is considered authoritarian or not depending on how her or his child answers to the question: "Do your parents let you make your own decisions about the people you hang around with?" A parent whose child answers "No" is classified as behaving in an authoritarian fashion; all others are nonauthoritarian.
} 
relationship between income inequality (defined as the 90th-10th percentile ratio of within-school family income) and authoritarian parenting. The figure shows that across schools, the proportion of parents adopting the authoritarian parenting style is decreasing with the median income and increasing with income inequality. Broadly speaking, parents are more likely to meddle in the choice of friends when there are more children from disadvantaged families present. The differences are quantitatively large. The same pattern emerges in multiple regressions where we simultaneously include median income and income inequality and control for parental characteristics. ${ }^{10}$ The results are robust to within-school regressions exploiting variations across cohorts.

Figure 2: Authoritarian Parenting and Neighborhood Characteristics
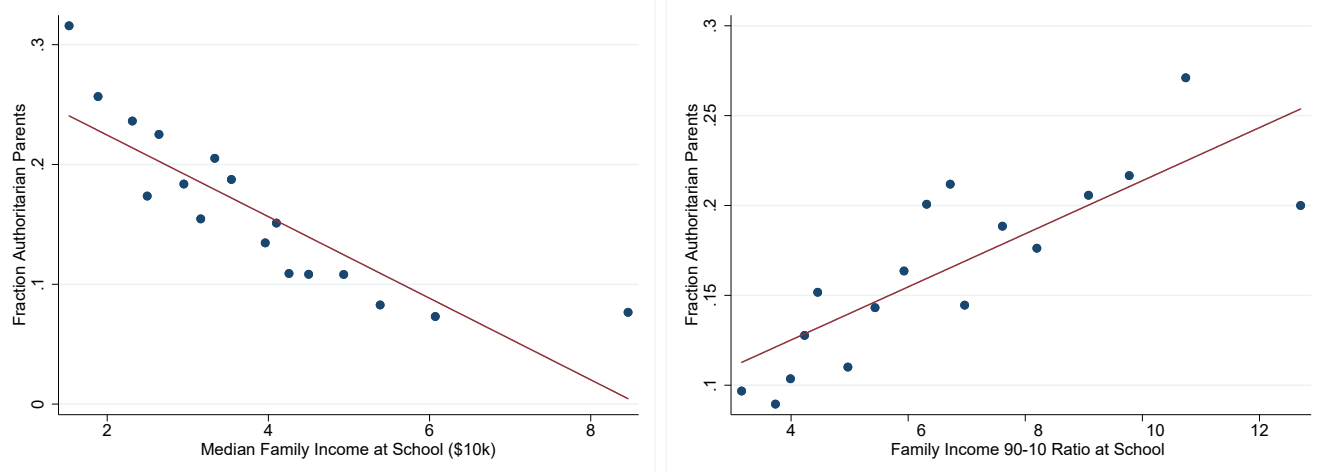

The figure shows how the incidence of the authoritarian parenting style varies with withinschool average family income (left panel) and inequality (right panel). Inequality is measured by the 90 th-10th percentile ratio of within-school family income.

Taking Stock. The evidence reviewed in this section has established the following points.

1. School closures have a negative impact on children's accumulation of skills,

\footnotetext{
${ }^{10}$ Similar patterns exist when one considers broader definitions of parenting styles. For instance, we consider the answer parents give to the question: "Of the following, which do you think is the most important thing for a boy/girl to learn? Be well-behaved, work hard, think for himself, help others, be popular." We define authoritarian parents as those who choose "be well-behaved," authoritative parents as those opting for "work hard," and permissive parents as those who choose "think for themselves." When we use these definitions, we continue to find that parents tend to be more permissive in wealthier and more equal neighborhoods, while they tend to be more authoritative and authoritarian in poorer and more unequal neighborhoods.
} 
and learning losses are particularly acute for children from low-income families.

2. Separation from peers reduces children's learning. School closures and social distancing also lead to more segregation in the peer environment for children from rich and poor families.

3. School closures place additional demands on parents, and richer and bettereducated parents are better positioned to meet these demands. In addition, parents' responses to their children's environment are likely to lead to more authoritarian parenting in less affluent neighborhoods.

We now construct and structurally estimate a model that allows us to quantify the joint effect of these factors on children's learning. The theory emphasizes potential heterogeneous effects across the socio-economic ladder.

\section{A Model of Skill Acquisition with Schools, Peers, and Parents}

The model is an extension of Agostinelli et al. (2020). We consider an economy where children live in neighborhood $n$ and attend school $s$. Human capital accumulation is determined by a technology of skill formation where a child's skills $\theta_{i, t}$ is a state variable whose evolution over time is affected by parental investments and peer effects. The distinctive features of our technology is that it allows for interactions between parents' behavior and peer effects, in the sense that parents can decide to interfere with the process of peer formation. Parental decisions crucially hinge on the social environment at the school and at the neighborhood level. In our empirical application the dynamics of the model corresponds to the four years of high school (grades 9 to 12). We first describe the model setup in normal times, and then discuss below how the Covid-19 pandemic temporarily changes the technologies and constraints faced by parents and children.

During normal times, children meet and interact with friends at school. Even though students live in different neighborhoods $n$, the neighborhood is not a relevant state variable during normal times because peer interactions take place at the school level. A school $s$ is characterized by a set $\mathcal{X}^{s}$ of attending children and their initial $(t=1)$ skill distribution. 
The timing of events in each period is as follows. At the beginning of the period, the child's current skill level $\theta_{i, t}$ is realized. Next, the child forms friendships with some of the other children of the same age in the same school. The characteristics of these friends (which affect skill formation) are summarized by the variable $\bar{\theta}_{i, t}$. The parent can now make two choices that affect the evolution of the child's skills and peers. First, the parent can undertake (authoritative) parenting investments $I_{i, t}$ that affect the child's skill formation. Second, the parent chooses her parenting style, $P_{i, t} \in\{0,1\}$, where $P_{i, t}=1$ means that the parent behaves in an authoritarian fashion by interfering in the child's next round of friendship decisions. At the beginning of the next period, the child's updated skill $\theta_{i, t+1}$ is realized and the new group of friends with the average skill $\bar{\theta}_{i, t+1}$ is formed. These events are repeated until the final year of high school. Then, the child enters adult life with skills $\theta_{i, T+1}$.

\subsection{Preferences of Parents and Children}

Parents' and children's preferences are as in Agostinelli et al. (2020), where we provide a more detailed discussion of the foundations of the preference structure. We employ the convention that lowercase variables correspond to the child and uppercase variables correspond to the parent. The individual state variables for a family are the child's skills $\theta_{i, t}$ and the characteristics of the child's peers $\bar{\theta}_{i, t}$. An additional aggregate state variable is the distribution of the children $\mathcal{X}^{s}$ in the school over skills at age $t$, which matters for friendship formation and peer effects. However, since in our analysis families do not switch schools, the aggregate state is taken as given by each family.

The parent decides on parenting style $\left(P_{i, t}\right.$ and $\left.I_{i, t}\right)$, and the child chooses peers, i.e., who to be friends with. We express the preferences of parent and child with value functions that summarize utility in a period after the child's current skills and peer group have already been realized so that the decisions concern the evolution of these variables into the next period.

The value function for child $i$ in neighborhood $n$ and school $s$ in period $t$ is given by:

$$
v_{t}^{n, s}\left(\theta_{i, t}, \bar{\theta}_{i, t}\right)=\max \left\{\mathrm{E}\left[u\left(\mathcal{F}_{i, t+1}\right) \mid \theta_{i, t}, \bar{\theta}_{i, t}\right]\right\} .
$$


Here $u\left(\mathcal{F}_{i, t+1}\right)$ captures the utility derived from peer interactions with the set of friends $\mathcal{F}_{i, t+1}$ chosen in period $t$, where $\mathcal{F}_{i, t+1} \subseteq \mathcal{X}^{n, s}$. The friend set $\mathcal{F}_{i, t+1}$ determines the next period's peer quality $\bar{\theta}_{i, t+1}$. The friendship decisions, in turn, hinge on both the child's and the parent's decisions. The expectation in the value function reflects the presence of taste shocks affecting the process of friendship formation. Current peer quality $\bar{\theta}_{i, t}$ enters the value function because it affects the evolution of the child's skills and the decisions of parents.

The parent's total utility in period $t$ is given by the value function:

$$
\begin{aligned}
V_{t}^{n, s}\left(\theta_{i, t}, \bar{\theta}_{i, t}\right) & =\max \left\{\mathrm { E } \left[U\left(I_{i, t}, P_{i, t}, \epsilon_{i, t}\right)+\right.\right. \\
Z & {\left.\left.\left[\lambda \tilde{u}\left(\theta_{i, t}, P_{i, t}\right)+(1-\lambda) u\left(\mathcal{F}_{i, t+1}\right)\right]+B V_{t+1}^{n, s}\left(\theta_{i, t+1}, \bar{\theta}_{i, t+1}\right) \mid \theta_{i, t}, \bar{\theta}_{i, t}\right]\right\} . }
\end{aligned}
$$

Here $U\left(I_{i, t}, P_{i, t}, \epsilon_{i, t}\right)$ is the parent's period utility, which depends on parenting style $\left(P_{i, t}\right.$ and $\left.I_{i, t}\right)$, chosen optimally by the parent. Utility also depends on taste shocks $\epsilon_{i, t}$, which ensure a smooth mapping from state variables into decisions. The parent also cares about the child, where $Z$ is the overall weight attached to the child's welfare. Parental concern about children has an altruistic and a paternalistic component. The altruistic component with weight $1-\lambda$ consists of the child's actual period utility $u\left(\mathcal{F}_{i, t+1}\right)$. The paternalistic component with weight $\lambda$ is the parent's own evaluation of the current actions and outcomes of the child. The paternalistic concern is focused on the child's accumulation of skills $\theta_{i, t}$, where we allow for the possibility that the parent's evaluation of the child's skill interacts with parenting style $P_{i, t}$. Hence, paternalistic utility enters as $\tilde{u}\left(\theta_{i, t}, P_{i, t}\right)$. Note that, at time $t$, the parent takes the quality of the child's current peers $\bar{\theta}_{i, t}$ as given, but the parent can influence future peer formation (and hence future peer quality $\bar{\theta}_{i, t+1}$ ) through the choice of parenting style $P_{i, t}$.

The continuation utility at the end of high school is identical to the child's continuation utility, and thus depends on $\theta_{T+1}$ :

$$
V_{T+1}^{n, s}=v_{T+1}^{n, s}\left(\theta_{i, T+1}\right),
$$

where the function $v_{T+1}^{n, s}\left(\theta_{T+1}\right)$ (corresponding to the child's utility as an adult) is taken as given and assumed to be identical across schools. 


\subsection{The Technology of Skill Formation}

The initial distribution of children's skills is drawn from the distribution $F^{n, s}\left(\theta_{i, 1}\right)$. This initial distribution would generally depend on families' socio-economic conditions, neighborhood effects, and earlier actions by parents and children, but is treated as exogenous here.

Subsequently, skills evolve as a function of family inputs and peer influences. For each child $i$, next period's skill $\theta_{i, t+1}$ depends on the current stock of skills $\theta_{i, t}$, a summary statistic of the quality of peers $\bar{\theta}_{i, t}$ (e.g., the average level of skills), parental investments $I_{i, t}$, and the parent's choice of whether to interfere in the child's choice of peers $P_{i, t} \in\{0,1\}$. The technology of skill formation is:

$$
\theta_{i, t+1}=s\left(\theta_{i, t}, \bar{\theta}_{i, t}, I_{i, t}, P_{i, t}\right) .
$$

The direct effect of parenting style $P_{i, t}$ in Equation (3) captures the impact of the quality of the parent-child relationship on skill accumulation.

\subsection{Endogenous Peer Selection}

We model the formation of friendships as a random utility model. Every period, each child meets all potential peers $\mathcal{X}^{n, s}$ in the school and can try to be friends with some of them. There is no capacity constraint in the number of friends nor any decreasing marginal utility to the number friendships. The potential utility $f_{i, j, t+1}$ that child $i$ would derive from forming a new friendship with $j \in \mathcal{X}^{n, s}$ is given by:

$$
f_{i, j, t+1}=g\left(\theta_{i, t+1}, \theta_{j, t+1}, P_{i, t}, \eta_{i, j, t+1}\right) .
$$

Here $\eta_{i, j, t+1}$ is an independent and identically distributed (i.i.d.) taste shock that guarantees that the probability that a friendship is established is a smooth function of fundamentals. Note that, in general, $\eta_{i, j, t+1} \neq \eta_{j, i, t+1}$, which captures the common situation where, say, child $i$ wants to be friends with $j$ but not vice versa. The utility from forming a friendship depends on both the own skill of child $i$ and the skill of the potential friend $j$. This specification allows for homophily bias in 
terms of skills. $^{11}$

The parenting style $P_{i, t}$ affects how much utility accrues to the child when it forms friendships with children of different skill levels. Since parents want to encourage skill formation, we assume that an authoritarian parenting style $\left(P_{i, t}=\right.$ 1) lowers the utility of befriending a low-skill peer relative to a high-skill one. This could be done by rewarding the child in some way for making "desirable" friends or by meting out punishments for befriending less desirable ones.

Friendships are subject to mutual agreement: a friendship between child $i$ and child $j$ is formed if and only if

$$
f_{i, j, t+1}>0 \& f_{j, i, t+1}>0
$$

where we normalize the value of not forming a friendship to zero. As already mentioned, $\mathcal{F}_{i, t+1} \subseteq \mathcal{X}^{n, s}$ denotes the set of friendships involving child $i$ in period $t+1$, i.e., the set of $j \in \mathcal{X}^{n, s}$ for which Equation (5) is satisfied. The friendship utility $u\left(\mathcal{F}_{i, t+1}\right)$ that determines the child's utility $(1)$ is then:

$$
u\left(\mathcal{F}_{i, t+1}\right)=\sum_{j \in \mathcal{F}_{i, t+1}} f_{i, j, t+1}
$$

\subsection{Friendship Formation in the First and Last Periods}

The value functions (1) and (2) in the first period (corresponding to 9th grade) depend on the initial quality of peers $\bar{\theta}_{i, 1}$. Rather than taking this state variable as parametric, we assume that only the initial distribution of skills is given and that friendships are formed through the endogenous process discussed above. Given data limitations, we assume that parents cannot affect the initial choice of friends. $^{12}$

In the last period $T=4$ (corresponding to 12th grade), the parental decision problem is different because the continuation utility $V_{T+1}^{n, s}$ does not depend on

\footnotetext{
${ }^{11}$ The homophily bias is a common tendency of people in social networks to be drawn toward others who are similar to them in some significant dimension (see e.g., McPherson, Smith-Lovin, and Cook 2001; Currarini, Jackson, and Pin 2009; Jackson 2010, and, in a context similar to ours, Agostinelli 2018).

${ }^{12}$ Formally, we set $P_{i, t-1}=0$ when evaluating Equation (4) and Equation (5) at time $t=1$.
} 
the quality of peers. This reflects that children have to form new peer groups after leaving high school, and at any rate these future peers are not observed in the Add Health data. Setting $P_{i, T}=1$ does not affect future peers' skills, and parenting style will be optimally chosen solely based only on the parents' taste shocks.

The functional forms for estimating the model in pre-pandemic times are as in Agostinelli et al. (2020) and are described in Appendix A.

\subsection{Covid-19 in the Model: School Closures and Social Distancing}

In this section, we discuss the effect of the Covid pandemic in the model. We model the Covid shock as affecting parameters in a single period (one year of school). We assume that parents and children correctly anticipate that things will return to normal in the following year. Even though the shock is temporary, its effects will be persistent, through the dynamics of a child's own skill accumulation and further ramifications through peer effects and parental responses.

To show where the pandemic-induced parameter changes appear in the model, we first describe the functional forms for the technology of skill formation and parental utility.

Technology of Skill Formation. The technology of skill formation (3) takes the following form:

$$
s\left(\theta_{i, t}, \bar{\theta}_{i, t}, I_{i, t}, P_{i, t}=p\right)=A_{p, t} \times H_{p}\left(\theta_{i, t}, \bar{\theta}_{i, t}, I_{i, t}\right),
$$

where $A_{p, t}$ is a total factor productivity term such that

$$
A_{p, t}=-\nu_{t}+\kappa_{t} \cdot\left(\psi_{0}+\psi_{1} \cdot t\right)+\psi_{2} \cdot p
$$


and the contributions of peers, initial human capital, and parental time to skill formation enter in a CES functional form:

$$
\begin{aligned}
& H_{p}\left(\theta_{i, t}, \bar{\theta}_{i, t}, I_{i, t}\right) \\
& \quad=\left[\alpha_{1, p} \theta_{i, t}^{\alpha_{4, p}}+\left(1-\alpha_{1, p}\right)\left[\alpha_{2, p} \bar{\theta}_{i, t}^{\alpha_{3, p}}+\left(1-\alpha_{2, p}\right)\left(I_{i, t}-\bar{I}\right)^{\alpha_{3, p}}\right]^{\frac{\alpha_{4, p}}{\alpha_{3, p}}}\right]^{\frac{\alpha_{5, p}}{\alpha_{4, p}}} .
\end{aligned}
$$

Consider, first, the total factor productivity term $A_{p}(t)$. In normal times, $\nu_{t}=0$ and $\kappa_{t}=1$. When schools are closed $(S C)$, we have $\nu_{t}=\nu_{t}^{S C} \geq 0$ and $\kappa_{t}=\kappa^{S C}<$ 1. Relative to the baseline case, productivity falls across the board by a factor $1-\kappa^{S C}$. In addition, there is a grade-specific productivity loss $\nu_{t}^{S C}$.

Consider, next, the term $H_{p}\left(\theta_{i, t}, \bar{\theta}_{i, t}, I_{i, t}\right)$. In normal times, $\bar{I}=0$, while during school closures, $\bar{I}=\bar{I}^{S C}>0$. The term $\bar{I}^{S C}$ (which is constant across parents) captures a minimum time requirement before their parental investment $I_{i, t}$ becomes productive. This term captures the basic time cost required to manage learning at home during school closures and can be thought of as providing inputs usually coming from teachers.

Parental Utility. Parents' period utility function in Equation (2) takes the form:

$$
U\left(I_{i, t}, P_{i, t}, \epsilon_{i, t}, T\right)=\delta_{1} \ln \left(T-I_{i, t}\right)+\delta_{2} P_{i, t}+\epsilon_{i, t}\left(P_{i, t}\right)
$$

In normal times, $T=1$ for all parents. In pandemic times, the time endowment is given by $T=T^{S C} \in\left\{\underline{\tau}^{S C}, \bar{\tau}^{S C}\right\}$, where $\bar{\tau}^{S C}>\underline{\tau}^{S C}$. Heterogeneity in the time endowment during the pandemic captures how the ability to work form home affects parents' ability to support their children's virtual learning.

Effect of School Closures in the Model. We now have all the pieces in place to summarize how the model captures the effects of school closures and social distancing on children's skill acquisition. The following changes are imposed in the pandemic period:

1. The switch to remote learning lowers the total factor productivity in the 
technology of skill formation (6). This is captured by two shocks. First, $\kappa_{t}=$ $\kappa^{S C}<1$ for all grades. Second, motivated by the evidence of disruptive effects of losing social ties in Section 2, we allow for a grade-specific shock $\nu_{t}$. In normal times, $\nu_{t}=0$ for all grades. During school closures, $\nu_{t}=$ $\nu_{t}^{S C} \geq 0$.

2. When schools are closed, peer interactions are confined to the neighborhood $n$ rather than the school $s$. The relevant state variable becomes the distribution of peer skills in the neighborhood $\mathcal{X}^{n}$.

3. The switch to remote learning requires parents to spend time on home schooling. We model this as a minimum time requirement $\bar{I}$ in the skill formation technology. The time investment $I_{i, t}$ is productive only as long as $I_{i, t} \geq \bar{I}$. In normal times, $\bar{I}=0$.

4. Finally, the time constraints faced by parents change during the pandemic. We capture this change by a shock to the time endowment $T$ in the period utility function (7). In particular, we normalize $T=1$ for every parent in normal times. During pandemic times, we allow the time endowment to be heterogeneous across parents $\left(T=T_{i}^{S C}\right)$. This feature captures the different situations of parents who have a flexible work arrangement and are able to work from home during the pandemic (where can they help their children with school) versus those that cannot. Work flexibility status is assumed to be an individual state variable rather than a choice.

\section{Model Estimation: Normal and Pandemic Times}

We build our analysis on Agostinelli et al. (2020), who estimate the baseline model based on the Add Health data set that follows a set of children through the high school years in the 1990s. We take the estimated model in Agostinelli et al. (2020) to represent skill accumulation in regular times. We then use additional evidence to discipline the shocks occurring during the Covid-19 crisis. For overall learning losses and inequality, we use information on changes in children's test scores during the crisis discussed in Section 2. For changes in the peer environment, we use data on differences in income inequality and peer composition 
at the school and neighborhood levels. We also use the reduced-form evidence on the effects of losing peer connections on education from the Add Health data, as described in Section 2. For parental inputs, we use survey evidence from AdamsPrassl et al. (2020a) on parental time use during the pandemic.

By combining these data sources, our model accounts for up-to-date evidence on parental behavior and children's education during the Covid-19 crisis. Doing this in the context of a structural model then allows us to take additional steps. First, we can simulate the model forward to project the impact of current changes on children's education by the time they finish high school, taking endogenous changes in peer effects and parental inputs into account. Second, we can use the structure of the model to decompose the sources of various changes, such as peer influences, parental influences, and changes to the productivity of schooling during school closures. Third, we can use our model for policy analysis.

\subsection{Properties of the Estimated Technology of Skill Formation}

We start by summarizing the properties of the estimated skill formation technology in normal times, since these are key determinants of the effect of the Covid shock.

The technology of skill formation is allowed to differ across parents adopting an authoritarian $(p=1)$ or nonauthoritarian $(p=0)$ parenting style-formally, all parameters in Equation (3.5) depend on $p$. Total factor productivity $A_{p}$ is lower when parents are authoritarian $\left(A_{1}<A_{0}\right)$, capturing the well-documented disruptive effects of an authoritarian parenting style on the process of skill formation. Moreover, for authoritarian parents the estimated elasticities of substitution in the $H_{p}$ function (6) are close to unity. Hence, $H_{p}$ is well-approximated by a Cobb-Douglas production function.

In contrast, the estimated elasticities in (6) are significantly different from unity for nonauthoritarian parents. The estimates imply that:

- Parental investment and peer quality are substitutes: nonauthoritarian parents spend more time with their children when the peer group is weak. 
- Parental investment and own child quality are complements: nonauthoritarian parents invest more time when the child has high skill.

These properties of the technology of skill formation imply that when children face a deteriorating peer environment, parents who adopt a nonauthoritarian parenting style will spend more time with their children to offset unfavorable peer effects.

Concerning the choice between being authoritarian or not, parents are prone to turn authoritarian when the peer environment worsens and when their child's own skill goes down.

\subsection{Calibration of Covid Effects in the Model}

Our calibration focuses on five model features that capture the Covid shock: (i) the Covid-related learning shock $\kappa^{S C}$; (ii) the disruptive effect of losing social ties at school $\nu^{S C}$; (iii) the change in peer quality during the school closure; (iv) the basic time cost for parents required to manage learning at home during the pandemic $\bar{I}^{S C}$; and (v) parents' heterogeneous time endowments during the pandemic $T_{i}^{S C}$. We assume that the time endowment during COVID can take two values $T_{i}^{S C} \in\left\{\bar{\tau}^{S C}, \underline{\tau}^{S C}\right\}$, where $\bar{\tau}^{S C}>\underline{\tau}^{S C}$, capturing the heterogeneity in work flexibility status among parents.

We divide the calibration exercise into two steps. In the first step, we externally calibrate the first three elements (i)-(iii) by matching the measured changes in learning and social interactions associated with school closures. In the second step of the calibration, we use the simulated method of moments to estimate the parameters in (iv)-(v) by targeting moments related to changes in parents' time allocation during the pandemic.

We carry out our calibration exercise under the assumption that the Covid shock lasts for one school year. This scenario matches the likely outcome in those parts of the United States where schools continue to be closed and are unlikely to reopen before vaccines are widely available in mid-2021. The Covid shock therefore changes model parameters for a single period, and subsequently all parameters return to their previous levels for the remaining periods. The one-time shock 
still has persistent effects due to changes in the children's skill accumulation and peer groups.

Calibrating Changes in Learning and Social Interactions during Covid. We first externally calibrate three new model's features capturing Covid-19 in the model.

- Covid learning shock $\kappa^{S C}$ : we calibrate the learning shock in our model based on the results in Maldonado and De Witte (2020), who use test score data from Belgium to estimate the impact of the Covid crisis on learning. According to their analysis, the 2020 cohort of children leaving primary school (grade 6) experienced a learning loss of approximately 0.2 standard deviations compared to the previous cohort. This Covid-induced learning loss translates into a learning (TFP) shock of $\kappa^{S C}=0.5$ in our framework. Given that Maldonado and De Witte (2020) consider the impact of school closures that lasted only a few months, this learning shock is a conservative estimate of the potential impact on learning of the entire pandemic. Still, erring on the conservative side is appropriate given that virtual instruction may have become more effective over time after the initial adjustment.

- Disruptive effect of losing social ties at school $\nu^{S C}$ : we use the estimated effects in Table 2 (Column 1) of losing peers in the transition from 8th grade to 9th grade. We divide children's skills during 9th grade into quartiles $Q(\theta) \in\{4,3,2,1\}$ corresponding to GPA grades $\mathrm{A}, \mathrm{B}, \mathrm{C}$, and $\mathrm{D}$, and then calibrate the disruptive effect as follows: $\nu^{S C}=-0.314+0.086 \cdot Q(\theta)$.

- Change peer quality during school closure: we calibrate the change in peer quality based on the evidence in Figure 1. We translate these findings in the following peer quality in the model during the pandemic: $\bar{\theta}^{S C}=0.1802+$ 0.0198 - Income Percentile.

Calibrating Changes in Time Endowments and Allocations. We use two sources to study the change in parental time inputs due to the outbreak of the pandemic. The Covid Inequality Project described in Adams-Prassl et al. (2020a) provides 
information on time spent on active childcare and homeschooling for a representative sample of US parents during the pandemic. As these data do not contain information for the pre-pandemic period, we complement them with data on parental time use drawn from the 2019 American Time Use Survey (2019 ATUS-CPS). For the purpose of comparability, we classify as parental time inputs the following activities in ATUS: physical care of children, homework and other school related activities, homeschooling, reading, playing (including arts, crafts, and sports), other educational activities, talking and listening to children, organization of activities, looking after children, attending events, picking up, dropping off or waiting for/with children, providing medical or other health care to children. ${ }^{13}$

We focus on two data moments to characterize the change in parental time inputs due to the outbreak of the pandemic. ${ }^{14}$ First, we consider on the average number of daily hours parents spend with children. Parental time with children has grown by a factor of about four, from an average of 1.26 daily hours in 2019 to 5.15 daily hours during the pandemic in 2020. Second, we focus on the relationship between family income and parental time inputs. ${ }^{15}$ Wealthier families report more parental time inputs than their less-affluent counterparts. The positive relation between family income and parental time inputs is apparent both in 2019 and 2020, but it strengthens with the outbreak of the Covid-19 crisis. The income effect on parental time inputs is almost four times larger during the pandemic than in 2019. ${ }^{16}$

\footnotetext{
${ }^{13}$ The analysis of parental time inputs should be interpreted with caution as it relies on the comparison of two different data sets with time variables that are similar but not identical across the two data sources.

${ }^{14}$ For the sake of comparability across data sets, parental time inputs refer to weekdays and to the sample of working parents.

${ }^{15}$ Due to the role of work flexibility in shaping parental time inputs during the pandemic, we rely on additional information provided by the Covid Inequality Project research team to map parental time with children, family income, and work flexibility. We start with additional evidence of a positive and significant effect of work flexibility on parental time inputs during the pandemic. Then, we combined the information on the effect of work flexibility on parental time inputs with the positive relationship between labor income and work flexibility shown in Adams-Prassl et al. (2020b) (Figure 14-a). Finally, using the Current Population Survey (CPS) for 2019 we convert labor income into family income and estimate the relationship between family income and parental time inputs during the Covid-19 crisis.

${ }^{16}$ For completeness, in 2020 the average effect of a $\$ 10,000$ change in family income on daily hours spent by a parent in activities with children amounts to 0.06 .
} 
Table 3: Calibration Fit for Parental Investments (Ratios of During vs. Before Pandemic)

\begin{tabular}{lcc}
\hline \hline & Data & Model \\
\hline Ratio of Mean Investments & 4.08 & 4.04 \\
Ratio of Income Gradient of Investments & 3.94 & 4.04 \\
\hline \hline
\end{tabular}

The table shows both data and simulated target moments for the calibration exercise. The first moment represents the ratio of the mean parental investments after and before Covid (2020 vs. 2019). The second moment is the ratio of the income gradients of parental investments after and before Covid (2020 vs. 2019).

Table 3 shows the two matched moments for this calibration exercise. The calibration recovers two structural parameters associated with the Covid shock: the basic time cost required to manage learning at home $\bar{I}^{S C}$, as well as the time endowment for parents who are able to work from home $\tau^{S C}$. We set $\underline{\tau}^{S C}=1$, that is, parents who cannot work from home have the same time endowment as before the crisis. In contrast, parents who can work from home have a higher endowment, $\bar{\tau}^{S C}>1$. The underlying assumption is that parents who can work from home have some ability to work and supervise their children's learning at the same time, which increase their effective time endowment (as in Alon et al. 2020).

Table 4: Calibrated Parameters: Time Cost and Time Endowment

\begin{tabular}{lc}
\hline \hline & Value \\
\hline Minimal Time Cost $\bar{I}^{S C}$ & 0.32 \\
Time Endowment of Work-from-Home Parents $\bar{\tau}^{S C}$ & 2.42 \\
\hline \hline
\end{tabular}

The table shows the values of the two calibrated parameters: the basic time cost required to manage learning at home $\left(\bar{I}^{S C}\right)$, as well as the time endowment for parents who are able to work from home $\left(\bar{\tau}^{S C}\right)$.

Table 4 shows the calibrated parameters. We find that approximately 30 percent of the pre-Covid time endowment needs to be devoted to the child as a basic parental time cost of remote learning. Moreover, we find that the effective time endowment available for childcare for parents who work from home is 2.4 times 
higher than the endowments of parents with in-person jobs.

\section{The Effect of a Pandemic in the Estimated Model}

Our estimated model matches well the evidence on children's skill acquisition, peer formation, and parental behavior during normal times. It also matches well the evidence on average learning losses, changes in the peer environment, and differential time constraints across richer and poorer parents during the Covid19 crisis. We can then use the estimated model to assess how school, peers, and parents contribute to educational inequality during the pandemic. We can also make forecasts for how human capital accumulation and educational inequality will evolve during the years following the crisis.

Peer Effects. Consider, first, the effect of school closure on peer effects. Figure 3 shows the change in the average GPA of the chosen friends broken down by the percentile of family income at the census block level. The average GPA falls for children from low-income census blocks and increases for children from highincome blocks. This is the result of several forces. First, during the pandemic there is a general decay in the learning process because of the impact of school closures on the productivity of the skill formation technology. Second, the effect varies greatly across the social ladder. Because the peer environment shifts from the school to the neighborhood level, socio-economic segregation increases, causing children living in low-income neighborhoods to have lower-achieving peers than in normal times. Inequality is further exacerbated by the different extent to which rich and poor parents can use their own time to compensate for the lack of in-school instruction. This causes an additional deterioration of the peer environment in low-income neighborhoods, where fewer parents can work from home and hence have less time to help their children.

Overall, peer effects deteriorate far more in low-income neighborhoods. In the richest neighborhoods there is no negative effect at all, partly because interactions move to the neighborhood level where children are more assortatively sorted. In other words, the children from the most affluent families only meet children with a similar background who on average are highly academically proficient. 
Figure 3: Simulated Effects of Covid on Endogenous Peer Effects

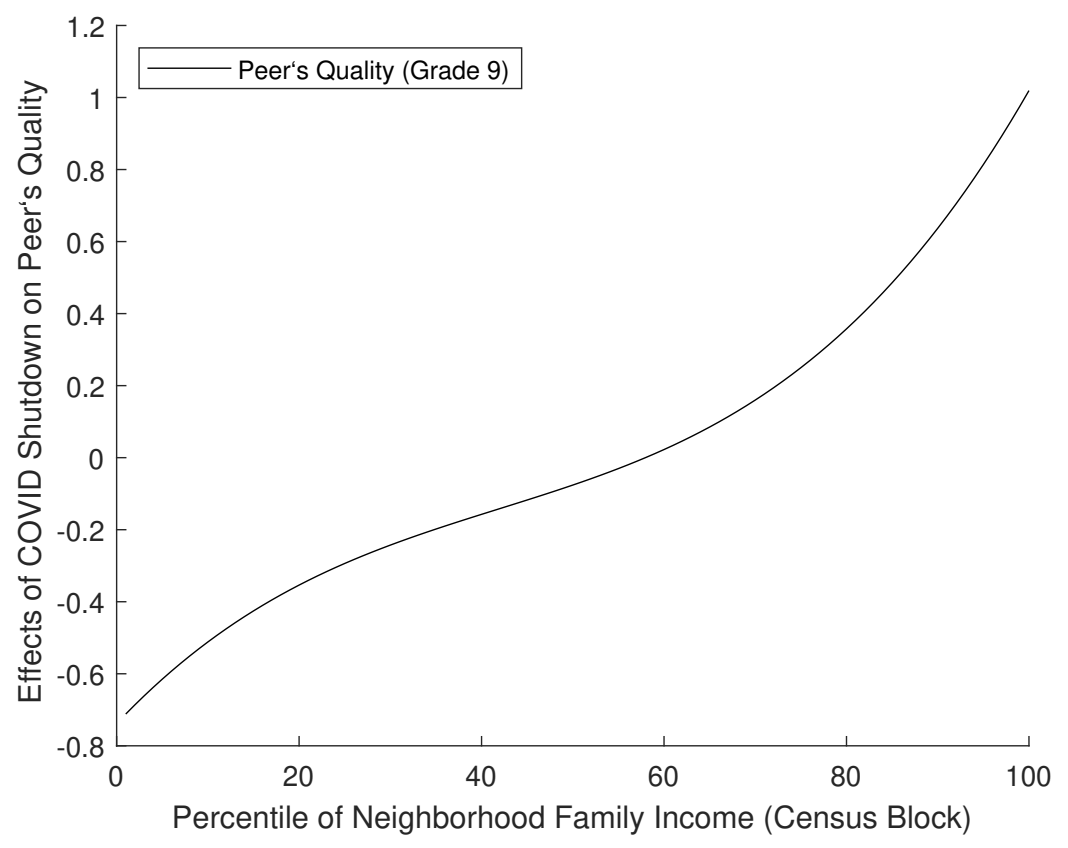

The figure shows the effect of Covid on the endogenous peer quality by neighborhood income. The y-axis displays the change in peer quality after the Covid shock (relative to baseline). The $\mathrm{x}$-axis represents the income percentile of the neighborhood where children live.

Parental Time Investments. Because in our estimated model parental investments are a substitute of peer effects (see Section 4.1), parents in more disadvantaged areas have an incentive to offset a deteriorating peer environment by spending more time on supporting their children's learning. Indeed, Figure A-1 in the Appendix shows that, absent other constraints, it is the parents living in poor neighborhoods who would increase their time investments the most during the pandemic. However, the pandemic has an additional effect: it frees time selectively for parents working from home. The flexibility of work arrangements hinges on a parent's occupation, which in turn is highly correlated with income.

Figure 4 shows the response of time investments for parents of 9th graders, taking into account the different time constraints people face. The time investment increases for all parents, largely because during the pandemic parents must devote a certain number of hours to help their children with school-related tasks. 
Figure 4: Simulated Effects of Covid on Parenting: Authoritative Investments

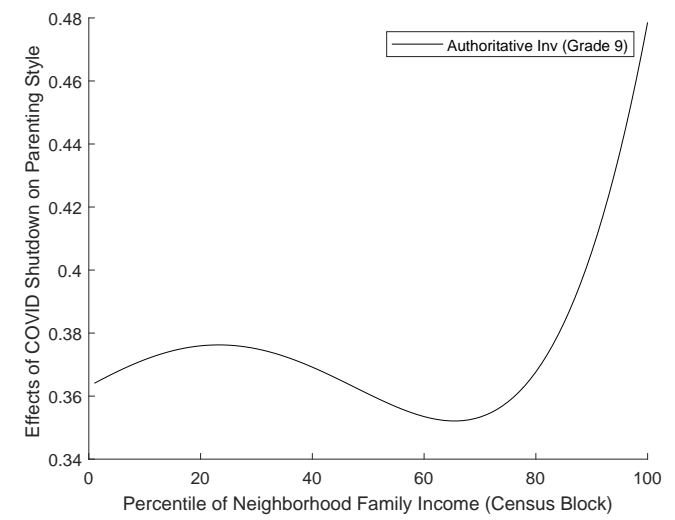

(a) Grade 9

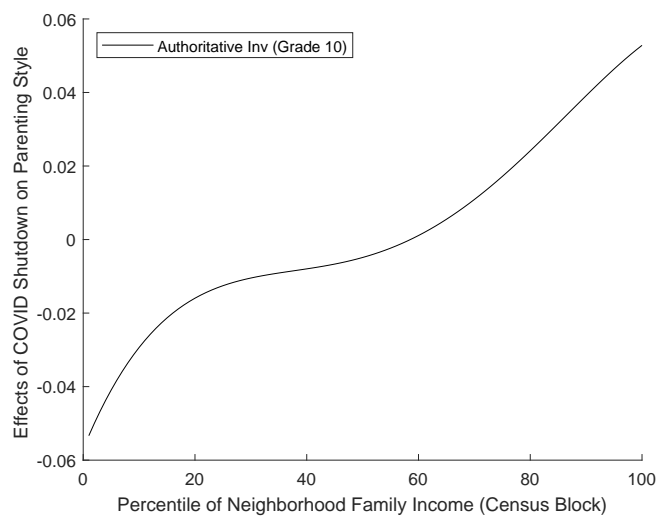

(b) Grade 10

The figure shows the effect of Covid on parental investments by neighborhood income. The y-axis displays the change in parental investments after the Covid shock (relative to baseline). The $x$-axis represents the income percentile of the neighborhood where children live.

However, the response varies across the socio-economic ladder, with a reverse pattern relative to the case in which parents face uniform constraints. There are no significant differences across the poorest 80 percent of neighborhoods. However, authoritative investments increase steeply in income for the top 20 percent. In the richest neighborhoods, where many parents can work from home, the response of parental investments is 50 percent larger compared to average parents, and 70 percent larger compared to the poorest parents.

One might have expected poorer parents to make up for the learning gap after the pandemic is over. However, this turns out not to be the case. The right-hand panel of Figure 4 shows the response when the children move to 10th grade after the pandemic is over. Changes in parental investments relative to the prepandemic baseline continue being steeply increasing in income. The reason is that in our estimated model authoritative investments are a substitute for peer effects but a complement to children's own skills. For parents living in the poorest neighborhoods, there is a discouragement effect arising from the lower attainment of their own children. In addition, when their children return to school, they are mixed with better peers. Both changes induce parents living in dis- 
advantaged neighborhoods to cut the authoritative investments relative to the pre-pandemic baseline. The situation is different for the children of richer parents. The skills of these children did not suffer a comparable setback during the school closure. Moreover, when they return to school these children interact with weaker peers. This induces rich parents living in affluent neighborhoods to increase the authoritative investments relative to the pre-pandemic baseline.

Authoritarian Parenting. Another part of the response generated by the Covid shock is an increase in authoritarian parenting. In the baseline economy, authoritarian parenting is prevalent among poorer families whose children are on average less proficient, while it is almost absent among richer families. Figure 5 shows that the pandemic exacerbates this pattern. In both grade 9 (during Covid) and grade 10 (after Covid), the authoritarian parenting style increases in poor neighborhoods, while remaining unchanged at a low level in richer neighborhoods. The difference in the response is quantitatively large. In the baseline economy, about 18 percent of parents adopt an authoritarian parenting style. For the poorest parents, the model predicts an increase in the prevalence of authoritarian parenting of 14 percentage points. The effect persists beyond the pandemic. To understand why the response is heavily skewed toward poor families, note that authoritarian parenting increases when peer effects deteriorate and when a child's own skills are lower. Both factors apply to poor families during Covid: their children suffer a learning loss and they are more exposed to the influence of low-achieving peers. While adopting the authoritarian parenting style is an individually rational choice in the model, it exerts a negative externality on other disadvantaged children, thereby contributing to wider educational inequality during the pandemic.

Skill Accumulation. Our analysis thus far has highlighted two main channels leading to skewed effects against the poor. The first is an increase in sorting associated with the fact that peer interactions move from the school to the neighborhood level. Because neighborhoods are more segregated than schools, the peer environment deteriorates for children living in poorer neighborhoods and improves for those living in richer neighborhoods. The second concerns parenting style and parental investments. In poor neighborhoods, parents become more 
Figure 5: Simulated Effects of Covid on Parenting: Authoritarian Parenting Style

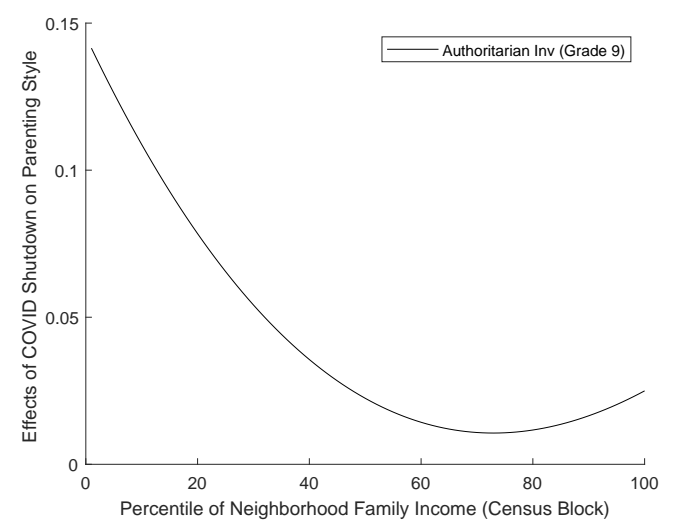

(a) Grade 9

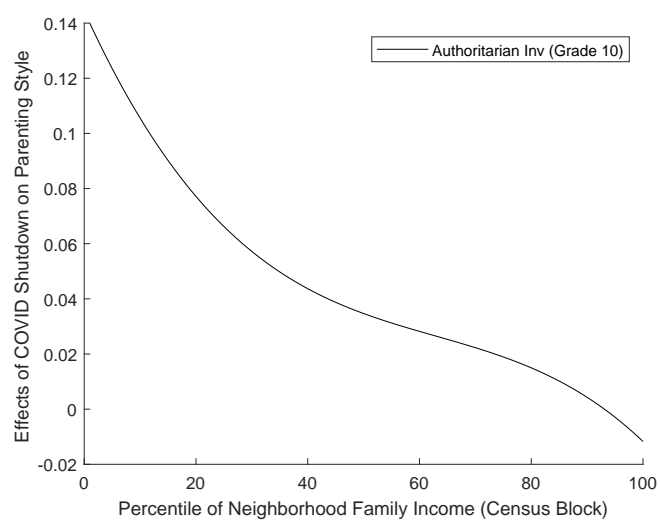

(b) Grade 10

The figure shows the effect of the pandemic on parenting style by neighborhood income. The $y$-axis displays the change in the fraction of authoritarian parents after the Covid shock (relative to baseline). The $\mathrm{x}$-axis represents the income percentile of the neighborhood where children live.

authoritarian, while in rich neighborhoods parents spend significantly more time with their children. This is the rational response to different time constraints and to the change in the peer environment. The pattern persists after schools reopen.

Figure 6 shows the effect of the Covid shock on the skill accumulation of 9th graders along with the simulated effect for the same children at the end of the high school. The initial impact in 9th grade is large and skewed. There are no significant effects on the skills of children living in the most affluent neighborhoodsfor the top decile of neighborhoods we even observe a slight improvement relative to baseline. For children living in rich neighborhoods, the negative effect of school closures is offset by an increase in parental investments along with an improvement in the peer environment. For children living in the poorest neighborhoods, the skill loss when entering 10th grade amounts to 0.6 standard deviations. ${ }^{17}$ Many poor working parents cannot respond to the lack of in-class teaching because they cannot work from home. In addition, parents turn more

\footnotetext{
${ }^{17}$ In terms of the GPA scale (which ranges from 1.0 for a straight-D student to 4.0 for a straightA student) this change corresponds to a decline of almost half a point; for example, a child who was a straight-B student before would now be getting a $C$ grade in almost half of the subjects.
} 
Figure 6: Simulated Effects of Covid on a Child's Skills

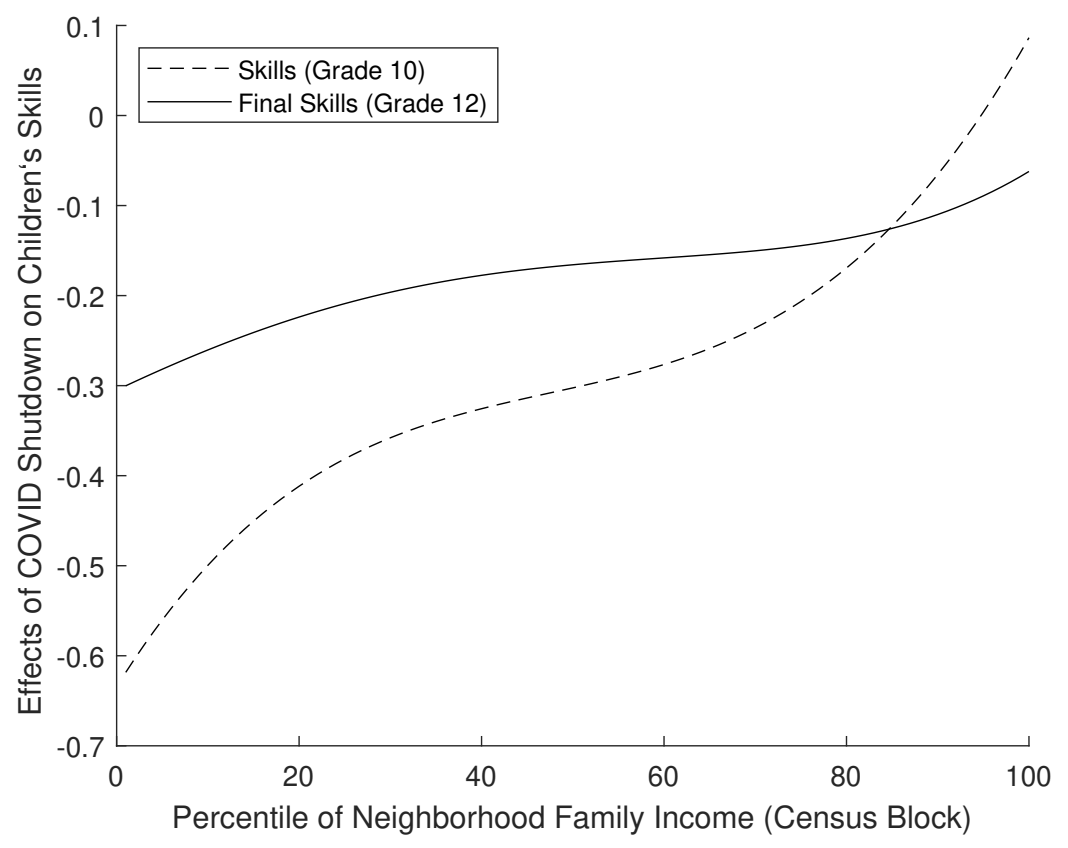

The figure shows the effect of Covid on children's skills by neighborhood income. The yaxis displays the change in children's skills after the Covid shock (relative to baseline). The units are in terms of a standard deviation of skills across children. The $x$-axis represents the income percentile of the neighborhood where children live.

authoritarian, which imposes a negative externality on the local environment that hits the most disadvantaged children especially hard.

Table 5 shows how each of the three channels (schools, peers, and parents) contributes to rising educational inequality during the pandemic. If we remove the negative learning shock during the pandemic (i.e., the downward shift in the skill accumulation technology that represents the direct effect of switching from in-person to virtual schooling) the income gradient in the impact of the crisis on education would be reduced by about a third. Leaving the learning shock in place but removing inequality in time constraints across parents (as if all parents could work from home, regardless of income), reduces the gradient by slightly more than 20 percent. The change to the peer environment has the largest impact: if we hold peer influences on learning constant at the pre-crisis level, the gradient is reduced by more than 60 percent. 
Table 5: Contribution of Covid Effects on Children's Skills by Income

\begin{tabular}{lccc}
\hline \hline & $\begin{array}{c}\text { No Learning } \\
\text { Shock }\end{array}$ & $\begin{array}{c}\text { No Peers } \\
\text { Shock }\end{array}$ & $\begin{array}{c}\text { No Extra Time } \\
\text { Constraints }\end{array}$ \\
\cline { 2 - 4 } & $-32.85 \%$ & $-61.94 \%$ & $-22.13 \%$ \\
\hline $\begin{array}{l}\text { Inequality of Covid Effects } \\
\text { by Income }\end{array}$ & & & \\
\hline \hline
\end{tabular}

The table shows the contribution of school, larges, and parents to the income gradient of the effect of the pandemic on skills in 12th grade in Figure 6. Each column shows the reduction in the income gradient when the mechanism is shut down.

We can also use the estimated model to trace out how children's skills evolve over the remaining high school years. Over time, the negative effect turns both smaller and less unequal. The children of richer families suffer some losses because they interact with weaker peers in school. Conversely, as schools reopen the children from disadvantaged backgrounds benefit from returning to school, which offers a less socially segregated environment and better peer effects than does the neighborhood. The long-run losses are about half as large as the shortrun losses (in percentage terms). Nevertheless, the outcome continues to be unequal. At the end of high school, the average human capital deficit is about 12 percent, ranging from 5 percent in the most affluent communities to 30 percent in the poorest ones. These are large long-run differences in a society already troubled by dramatic gaps in opportunities.

\section{Policy Implications}

The severe learning losses already documented during the Covid-19 pandemic and the prospect of widening educational inequality call for well-designed policies that can help offset some of these effects. These policy questions are relevant not just for the ongoing crisis, but also for preparing for the possibility of another pandemic in the near future. In terms of consequences for education, keeping schools open during a pandemic would be desirable, but clearly this has to be weighed against the need to control the pandemic and to stop infections from spreading. Still, policymakers face tradeoffs even during a crisis, and an analysis of the consequences of the pandemic for children's education can help inform these tradeoffs. 
A general point about the impact on children's education is that the impacts are hard to undo and can have lifelong consequences for children's future prospects. Unlike a business that can be compensated for pandemic-induced losses, there is no magic trick for making up learning losses incurred during the crisis. This observation suggests that keeping schools open during the crisis should have a higher priority than, say, opening bars and restaurants that can be supported with other means. While this is the approach already taken by a number of countries, other communities, including many US states, have taken the opposite tack of prioritizing keeping businesses open over schools.

Beyond fully opening all schools, another option consists of partial openings, with only a fraction of students attending in-person school to allow for better social distancing. Our analysis can inform which groups would particularly benefit from in-person schooling. One potential criterion is whether a child's parents are able to work from home and support virtual learning. The children of essential workers who cannot work from home during the crisis are especially vulnerable. Some countries have already experimented with providing childcare specifically for the children of essential workers. But the ability to work from home could be used as a more general criterion for who should attend in-person schooling.

In terms of peer effects, our empirical results suggest that children who already have to adjust to a new peer environment because they are switching schools are especially vulnerable to negative repercussions of reduced peer interactions. This channel would suggest that students who enter high school (9th grade) should have a higher priority for in-person schooling compared to 10th or 11th graders who have already established peer networks in high school. The evidence is suggestive that the same would be true for children transitioning from elementary to middle school, although our data does not directly speak to this issue.

Beyond the specific structure of our analysis, it is also worth asking whether additional schooling could be provided at a later time to make up for some of the learning losses during the pandemic. School children in the United States and other countries usually have long summer breaks. It now appears likely that by the summer of 2021 safe, in-person schooling will be possible again. Extending school throughout the summer at least for the more vulnerable groups of chil- 
dren might be the last chance to offset at least some of the substantial learning losses that are otherwise likely to have lifelong effects. Investing in such programs would be expensive, but not excessively so relative to support already given to individuals and businesses. Providing a detailed cost-benefit analysis for such programs should be a high priority for researchers in the coming months.

\section{Conclusions}

The Covid-19 pandemic has brought about the largest disruption to children's learning in many countries in generations. Empirical evidence suggests that learning losses, once accrued, are difficult to fully offset later on, suggesting that the current crisis will affect the economic opportunities of today's children for decades to come. An additional concern is the impact of the pandemic on educational inequality. As Horace Mann famously put it, in regular times schools play a role as a "great equalizer" - they provide a single learning environment and integrated peer groups for children from different backgrounds. The Covid-19 pandemic puts this role of schools at risk.

This paper builds on the observation that children's learning depends not just on schools, but also on inputs provided by their parents and on interactions with their peers. To assess how a pandemic such as the current one affects overall learning and educational inequality, all three channels should be taken into account. We provide such an analysis by using a quantitative model of skill acquisition that explicitly models the behavior of parents, children, and children's peers. We calibrate this model to match evidence from the current crisis, and use the estimated model to shed light on how each factor contributing to children's overall success in education is modified during the pandemic.

The main conclusion from our analysis is that each of the channels we consider contributes to higher educational inequality. Children from poorer families do relatively worse with virtual compared to regular schooling; they are less likely to benefit from positive peer spillovers during the crisis; and their parents are less likely to work from home and hence less likely to be able to provide them with maximum support for virtual schooling. The end result is that learning gaps 
grow during the pandemic. Our model also predicts that wider achievement gaps will persist until children finish high school, suggesting that children's longterm prospects are at risk.

Our findings suggest that policy options that could counteract some of these changes, such as extending in-person schooling for at-risk children throughout the summer months, should be considered. Our findings also call for more empirical and structural research on the education crisis brought about by the pandemic. There is now some direct evidence on changes in children's learning during the pandemic, but for other aspects such as changes to peer effects our analysis relies primarily on extrapolation from earlier evidence. More comprehensive evidence on how children's peer environments and parental interactions change during the pandemic will put researchers and policymakers in a better position to evaluate possible countermeasures.

\section{References}

Adams-Prassl, Abi, Teodora Boneva, Marta Golin, and Christopher Rauh. 2020a. "Inequality in the Impact of the Coronavirus Shock: Evidence From Real Time Surveys." Journal of Public Economics 189:104245.

- 2020b. "Work That Can Be Done from Home: Evidence on Variation within and across Occupations and Industries." IZA Discussion Paper 13374.

Agostinelli, Francesco. 2018. "Investing in Children's Skills: An Equilibrium Analysis of Social Interactions and Parental Investments." Unpublished Manuscript, University of Pennsylvania.

Agostinelli, Francesco, Matthias Doepke, Giuseppe Sorrenti, and Fabrizio Zilibotti. 2020. "It Takes a Village: The Economics of Parenting with Neighborhood and Peer Effects." NBER Working Paper 27050.

Agostinelli, Francesco, and Matthew Wiswall. 2016. "Estimating the Technology of Children's Skill Formation." NBER Working Paper 22442.

Alon, Titan, Matthias Doepke, Jane Olmstead-Rumsey, and Michèle Tertilt. 2020. “This Time It's Different: The Role of Women's Employment in a Pandemic Recession." NBER Working Paper 27660. 
Andrew, Alison, Sarah Cattan, Monica Costa Dias, Christine Farquharson, Lucy Kraftman, Sonya Krutikova, Angus Phimister, and Almudena Sevilla. 2020. “Inequalities in Children's Experiences of Home Learning during the COVID-19 Lockdown in England." Fiscal Studies 41 (3): 653-683.

Attanasio, Orazio, Sarah Cattan, Emla Fitzsimons, Costas Meghir, and Marta Rubio-Codina. 2020. "Estimating the Production Function for Human Capital: Results from a Randomized Control Trial in Colombia." American Economic Review 110 (1): 489-485.

Calvó-Armengol, Antoni, Eleonora Patacchini, and Yves Zenou. 2009. "Peer Effects and Social Networks in Education." Review of Economic Studies 76 (4): 1239-1267.

Chetty, Raj, and Nathaniel Hendren. 2018a. "The Impacts of Neighborhoods on Intergenerational Mobility I: Childhood Exposure Effects." Quarterly Journal of Economics 133 (3): 1107-1162.

_ 2018b. “The Impacts of Neighborhoods on Intergenerational Mobility II: County-Level Estimates." Quarterly Journal of Economics 133 (3): 1163-1228.

Chetty, Raj, Nathaniel Hendren, and Lawrence F. Katz. 2016. “The Effects of Exposure to Better Neighborhoods on Children: New Evidence from the Moving to Opportunity Experiment." American Economic Review 106 (4): 855-902.

Cunha, Flavio, James J. Heckman, and Susanne M. Schennach. 2010. “Estimating the Technology of Cognitive and Noncognitive Skill Formation." Econometrica 78 (3): 883-931.

Currarini, Sergio, Matthew Jackson, and Paolo Pin. 2009. “An Economic Model of Friendship: Homophily, Minorities and Segregation." Econometrica 77 (4): 1003-1045.

Del Boca, Daniela, Christopher Flinn, and Matthew Wiswall. 2014. "Household Choices and Child Development." Review of Economic Studies 81 (1): 137-185.

Di Pietro, Giorgio, Federico Biagi, Patricia Costa, Karpiński Zbigniew, and Jacopo Mazza. 2020. “The Likely Impact of COVID-19 on Education: Reflections Based on the Existing Literature and International Datasets." EUR 30275 EN, Publications Office of the European Union, Luxembourg. 
Doepke, Matthias, Giuseppe Sorrenti, and Fabrizio Zilibotti. 2019. “The Economics of Parenting." Annual Review of Economics 11:55-84.

Doepke, Matthias, and Fabrizio Zilibotti. 2020. "COVID-19 and Children's Education: The Time to Plan Large-scale Summer Learning Programs is Now." Psychology Today.

Downey, Douglas B., Paul von Hippel, and Beckett A. Broh. 2004. “Are Schools the Great Equalizer? Cognitive Inequality during the Summer Months and the School Year." American Sociological Review 69 (5): 613-635.

Durlauf, Steven N., and Yannis M. Ioannides. 2010. "Social Interactions." Annual Review of Economics 2 (1): 451-478.

Eckert, Fabian, and Tatjana Kleineberg. 2019. "Can We Save the American Dream? A Dynamic General Equilibrium Analysis of the Effects of School Financing on Local Opportunities." Unpublished Manuscript, Yale University.

Engzell, Per, Arun Frey, and Mark Verhagen. 2020. “Learning Inequality During the Covid-19 Pandemic." Mimeo.

Epple, Denis, and Richard E. Romano. 2011. "Peer Effects in Education: A Survey of the Theory and Evidence." In Handbook of Social Economics, edited by Jess Benhabib, Alberto Bisin, and Matthew O. Jackson, Volume 1, 10531163. Amsterdam: Elsevier.

Fogli, Alessandra, and Veronica Guerrieri. 2018. "The End of the American Dream? Inequality and Segregation in US Cities." Unpublished Manuscript, University of Chicago.

Fuchs-Schündeln, Nicola, Alexander Ludwig, Dirk Krueger, and Irina Popova. 2020. "The Long-Term Distributional and Welfare Effects of Covid-19 School Closures." NBER Working Paper 27773.

Grewenig, Elisabeth, Philipp Lergetporer, Katharina Werner, Ludger Woessmann, and Larissa Zierow. 2020. "COVID-19 and Educational Inequality: How School Closures Affect Low-and High-Achieving Students." IZA Discussion Paper 13820. 
Jackson, Matthew. 2010. Social and Economic Networks. Princeton University Press.

Kuhfeld, Megan, James Soland, Beth Tarasawa, Angela Johnson, Erik Ruzek, and Jing Liu. 2020a. "Projecting the Potential Impact of COVID-19 School Closures on Academic Achievement." Educational Researcher 49 (8): 549-565.

Kuhfeld, Megan, Beth Tarasawa, Angela Johnson, Erik Ruzek, and Karyn Lewis. 2020b. "Learning During COVID-19: Initial Findings on Students' Reading and Math Achievement and Growth." NWEA.

List, John, Fatemeh Momeni, and Yves Zenou. 2019. “Are Estimates of Early Education Programs Too Pessimistic? Evidence from a Large-Scale Field Experiment that Causally Measures Neighbor Effects." CEPR Discussion Paper 13725 .

Maldonado, Joana Elisa, and Kristof De Witte. 2020. "The Effect of School Closures on Standardised Student Test Outcomes." KU Leuven Discussion Paper Series 20.17.

McCombs, Jennifer Sloan, John F. Pane, Catherine H. Augustine, Heather L. Schwartz, Paco Martorell, and Laura Zakaras. 2014. "Ready for Fall? NearTerm Effects of Voluntary Summer Learning Programs on Low-Income Students' Learning Opportunities and Outcomes." Santa Monica, CA: RAND Corporation.

McPherson, Miller, Lynn Smith-Lovin, and James Cook. 2001. "Birds of a Feather: Homophily in Social Networks." Annual Review of Sociology 27:415444.

Mongey, Simon, Laura Pilossoph, and Alex Weinberg. 2020. “Which Workers Bear the Burden of Social Distancing Policies?" NBER Working Paper 27085.

Sacerdote, Bruce. 2011. "Peer Effects in Education: How Might They Work, How Big Are They and How Much Do We Know Thus Far?" In Handbook of the Economics of Education, edited by Eric A. Hanushek, Stephen Machin, and Ludger Woessman, Volume 3, 249-277. Amsterdam: Elsevier. 


\section{Appendices}

\section{A Functional Forms for Estimation}

To estimate the model, we impose functional forms and restrictions that allow us to summarize the model by a list of parameters.

Initial Conditions. The initial distribution of children skills within each school $s$ is drawn from a log-normal distribution. This specification captures the initial (and to us unobserved) sorting of families into different schools characterized by different initial distributions of children's skills. We define the initial conditions for each school $s$ as follows:

$$
\ln \theta_{i, 1} \sim N\left(\mu^{s},\left(\sigma^{s}\right)^{2}\right)
$$

where $\mu^{s}$ and $\sigma^{s}$ represent the school-specific mean and the standard deviation of the log-skills.

Similarly, initial conditions at the neighborhood level (which are relevant during the pandemic are given by:

$$
\ln \theta_{i, 1} \sim N\left(\mu^{n},\left(\sigma^{n}\right)^{2}\right)
$$

Once the initial heterogeneity of children's skills within the school is realized, children select their initial peer group according to their preferences for friends (Equation (4)). At this stage, the initial vector of state variables $\left\{\theta_{i, 1}, \bar{\theta}_{i, 1}\right\}$ is determined, and the dynamic parent-child interaction starts according to the model described above.

Technology of Skill Formation. We parameterize the technology of skill formation with the following nested CES production function:

$$
s\left(\theta_{i, t}, \bar{\theta}_{i, t}, I_{i, t}, P_{i, t}=p\right)=A_{p}(t) \times H_{p}\left(\theta_{i, t}, \bar{\theta}_{i, t}, I_{i, t}\right),
$$

where $p \in\{0,1\}, A_{p}(t)=\exp \left(\psi_{0}+\psi_{1} \cdot t+\psi_{2} \cdot p\right)$, and

$$
H_{p}\left(\theta_{i, t}, \bar{\theta}_{i, t}, I_{i, t}\right)=\left[\alpha_{1, p} \theta_{i, t}^{\alpha_{4, p}}+\left(1-\alpha_{1, p}\right)\left[\alpha_{2, p} \bar{\theta}_{i, t}^{\alpha_{3, p}}+\left(1-\alpha_{2, p}\right) I_{i, t}^{\alpha_{3, p}}\right]^{\frac{\alpha_{4, p}}{\alpha_{3, p}}}\right]^{\frac{\alpha_{5, p}}{\alpha_{4, p}}} .
$$

Note that all parameters of the skill formation technology depend on $p$, namely, whether the parent chooses an authoritarian parenting style. First, this affects the total factor pro- 
ductivity $A_{p}(t)$, capturing the potential disruptive effect of authoritarian parenting on the parent-child relationship documented by the developmental psychology literature. Our estimation below indeed finds that $\psi_{2}<0$, i.e., an authoritarian parenting style depresses skill accumulation. Second, parenting style affects the parameters $\alpha_{1, p}$ and $\alpha_{2, p}$, capturing the weights of the different inputs. Our estimation finds that the authoritarian style attenuates the influence of peers. Third, an authoritarian parenting style also affects the elasticity-of-substitution parameters $\alpha_{3, p}$ and $\alpha_{4, p}$ and the returns-to-scale parameter $\left(\alpha_{5, p}\right)$. Here the data suggest the parenting style determines whether peer effects are a substitute or a complement to other inputs in the production of skills.

Parent's Preferences. We specify the parent's period utility in (2) as follows:

$$
U\left(I_{i, t}, P_{i, t}, \epsilon_{i, t}\right)=\delta_{1} \ln \left(1-I_{i, t}\right)+\delta_{2} P_{i, t}+\epsilon_{i, t}\left(P_{i, t}\right),
$$

where $\delta_{1}$ and $\delta_{2}$ define the disutility of authoritative investment and of engaging in an authoritarian parenting style, respectively, and $\epsilon_{i, t}\left(P_{i, t}\right)$ is a taste shock that is conditional on the parenting style. We assume that this shock follows a type-I extreme value distribution. The paternalistic utility of the parent takes the following form:

$$
\tilde{u}\left(\theta_{i, t}, I_{i, t}, P_{i, t}\right)=\delta_{3} \ln \left(\theta_{i, t}\right) \cdot\left(1+\delta_{4} P_{i, t}\right)
$$

where $\delta_{3}$ captures the level of the parent's paternalistic enjoyment of the child's skills, which may depend on the parenting style through parameter $\delta_{4}$. The utility derived from the child's adult skills $\theta_{i, T+1}$ takes the same form as the period-by-period paternalistic utility from skills:

$$
V_{T+1}^{n, s}=\delta_{3} \ln \left(\theta_{i, T+1}\right) .
$$

In the empirical model, we set $Z=B=1$. This is without loss of generality. An increase in either $B$ or $Z$ is equivalent to a proportional decrease in cost parameters $\delta_{1}$ and $\delta_{2}$. Changing $B$ and/or $Z$ would affect the numerical estimates of those parameters without altering the model fit or the counterfactual experiments.

Child's Preferences. The (marginal) utility child $i$ earns from being friends with child $j$ relative to not being friends with $j$ is:

$$
\begin{aligned}
f_{i, j, t+1}=\gamma_{0}+\gamma_{1} \ln \theta_{i, t+1} & +\gamma_{2} \ln \theta_{j, t+1}+\gamma_{3}\left(\ln \theta_{i, t+1}-\ln \theta_{j, t+1}\right)^{2} \\
& +\gamma_{4} \mathbb{1}\left(\theta_{j, t+1}<\theta_{i, t+1}\right)\left(\ln \theta_{i, t+1}-\ln \theta_{j, t+1}\right)^{2} P_{i, t}+\eta_{i, j, t+1}
\end{aligned}
$$


Here, $\eta_{i, j, t+1}$ is a random taste shock for being friends with child $j$, which we assume to be i.i.d. standard logistic distributed. The terms $\gamma_{1} \ln \theta_{i, t+1}$ and $\gamma_{2} \ln \theta_{j, t+1}$ capture, respectively, the effect of child $i$ 's and child $j$ 's skills on the utility child $i$ earns from being friends with child $j$, where $\gamma_{1}$ and $\gamma_{2}$ are parameters that will be estimated. The quadratic term $\left(\ln \theta_{i, t+1}-\ln \theta_{j, t+1}\right)^{2}$ captures potential homophily bias in the formation of friends. A negative coefficient $\gamma_{3}<0$ would imply that the higher the difference in skills between the two children, the lower the utility for child $i$ to be friends with child $j$.

The coefficient $\gamma_{4}$ captures the effect of an authoritarian parenting style on the preferences for child $j^{\prime}$ 's skills. In particular, if $\gamma_{4}<0$, authoritarian parenting imposes a penalty whenever the child is friends with a lower-skill peer, where the penalty increases with the GPA gap between the two children. This formulation captures the idea that parental intervention (through, e.g., moral suasion, threat of punishment, or incentives) is designed to improve the quality of the child's peer selection.

We can now characterize the conditional probability that a friendship link between child $i$ and child $j$ is formed as: $:^{18}$

$$
\operatorname{Pr}\left(j \in \mathcal{X}_{i, t+1} \mid \theta_{i, t+1}, P_{i, t}, \theta_{j, t+1}, P_{j, t}\right)=\frac{\exp \left(\Gamma_{i, j}\right)}{1+\exp \left(\Gamma_{i, j}\right)} \frac{\exp \left(\Gamma_{j, i}\right)}{1+\exp \left(\Gamma_{j, i}\right)},
$$

where:

$$
\begin{aligned}
\Gamma_{i, j}=\gamma_{0}+\gamma_{1} \ln \theta_{i, t+1}+\gamma_{2} \ln \theta_{j, t+1}+ & \gamma_{3}\left(\ln \theta_{i, t+1}-\ln \theta_{j, t+1}\right)^{2} \\
& +\gamma_{4} \mathbb{1}\left(\theta_{j, t+1}<\theta_{i, t+1}\right)\left(\ln \theta_{i, t+1}-\ln \theta_{j, t+1}\right)^{2} P_{i, t}, \\
\Gamma_{j, i}=\gamma_{0}+\gamma_{1} \ln \theta_{j, t+1}+\gamma_{2} \ln \theta_{i, t+1}+ & \gamma_{3}\left(\ln \theta_{j, t+1}-\ln \theta_{i, t+1}\right)^{2} \\
& +\gamma_{4} \mathbb{1}\left(\theta_{i, t+1}<\theta_{j, t+1}\right)\left(\ln \theta_{i, t+1}-\ln \theta_{j, t+1}\right)^{2} P_{j, t} .
\end{aligned}
$$

The presentation of the parent's and child's preferences completes the description of the effects of parenting style in our model. To summarize, authoritarian parenting has a direct effect on the technology of skill formation given the current child's skill and peers. In

\footnotetext{
${ }^{18}$ The conditional probability in Equation (A-6) might suggest a potential strategic interaction between parents when deciding about their own parenting style. However, under our assumptions, only the parent of the higher-skill child can actively affect the probability in Equation (A-6), so there is in fact no strategic interaction among parents. Note that in our model parents have an additional motive to invest in their children's skills, namely, to give them more opportunities to condition their children's choice of peers in the future.
} 
addition, authoritarian parenting affects the process of peer formation by discouraging the child from choosing low-skill friends. Our estimates below imply that, conditional on an existing set of friends, an authoritarian parenting style entails productivity losses in the skill formation technology. The reason some parents still choose to be authoritarian must then lie in the benefits of an improved quality of future peers. It follows from this argument that in wealthy and homogeneous schools, where most potential friends are highly skilled and there is little risk that one's child might associate with low-skill peers, the cost of an authoritarian parenting style is high while the benefit is small. Conversely, parents will tend to be authoritarian in schools where children face a high risk of exposure to low-skill peers. 


\section{A Additional Figures and Tables}

Table A-1: Effect of Peer Separation on Child's GPA by Gender

\begin{tabular}{|c|c|c|c|c|}
\hline & \multicolumn{4}{|c|}{ Change in GPA (from Grade 8 to Grade 9) } \\
\hline & \multicolumn{2}{|c|}{ Child is Boy } & \multicolumn{2}{|c|}{ Child is Girl } \\
\hline & $(1)$ & $(2)$ & $(3)$ & $(4)$ \\
\hline \multirow[t]{2}{*}{ N. of Peers who Left } & $-0.100^{*}$ & $-0.124^{*}$ & $-0.100^{* *}$ & -0.080 \\
\hline & $(0.059)$ & $(0.073)$ & $(0.049)$ & $(0.052)$ \\
\hline $\mathrm{N}$ & 559 & 559 & 676 & 676 \\
\hline Controls & Yes & Yes & Yes & Yes \\
\hline School F.E. & No & Yes & No & Yes \\
\hline
\end{tabular}

The table shows the disruptive effects by gender of losing social ties in the transition from middle school to high school. The outcome is the change in a child's GPA during the transition from middle school to high school. In all the columns, the independent variable is the number of friends that a child lost. In columns (1)-(2), consider the sample of female students, while in columns (3)-(4) we consider the sample of male students. 
Table A-2: Effect of Peer Separation on Child's GPA

Change in GPA

(1)

(2)

(3)

\begin{tabular}{lccc} 
Grade $8(\mathrm{t}-1) \times$ N. of Peers who Left & $-0.105^{* * *}$ & $-0.106^{* * *}$ & $-0.111^{* * *}$ \\
& $(0.040)$ & $(0.040)$ & $(0.039)$ \\
Grade $7(\mathrm{t}-1) \times \mathrm{N}$. of Peers who Left & 0.001 & 0.004 & -0.021 \\
& $(0.052)$ & $(0.052)$ & $(0.049)$ \\
Grade $9(\mathrm{t}-1) \times$ N. of Peers who Left & -0.028 & -0.030 & -0.014 \\
& $(0.042)$ & $(0.042)$ & $(0.036)$ \\
Grade $10(\mathrm{t}-1) \times$ N. of Peers who Left & -0.033 & -0.034 & -0.013 \\
& $(0.025)$ & $(0.025)$ & $(0.023)$ \\
Grade $11(\mathrm{t}-1) \times$ N. of Peers who Left & 0.039 & 0.038 & $0.055^{*}$ \\
& $(0.025)$ & $(0.025)$ & $(0.032)$ \\
\hline N & 7611 & 7611 & 7611 \\
Controls & No & Yes & Yes \\
School F.E. & No & No & Yes \\
\hline \hline
\end{tabular}

The table shows the disruptive effects by grade of losing social ties in the transition from middle school to high school. The outcome is the change in a child's GPA from Wave I survey to Wave II survey. In all the columns, the independent variable is the number of friends that a child lost, interacted with the grade in which children were enrolled to during Wave I. 
Table A-3: Balance Test on Peers who Left

\begin{tabular}{lccc}
\hline \hline & & & \\
& \multicolumn{3}{c}{ Peers' GPA (t-1) } \\
\hline & & $(2)$ & $(3)$ \\
& & & \\
One or More Peers Left & 0.013 & 0.024 & -0.017 \\
& $(0.041)$ & $(0.038)$ & $(0.029)$ \\
\hline N & 1230 & 1230 & 1230 \\
Controls & No & Yes & Yes \\
School F.E. & No & No & Yes \\
\hline Mean Cohort GPA & 2.90 & & \\
Mean Peers Left GPA & 2.81 & & \\
P-value & 0.065 & & \\
\hline \hline
\end{tabular}

The table shows the balance test for the quality of peers who left. Each column shows a regression coefficient, where the dependent variable is the Peers' GPA during Wave I survey, while the independent variable is whether or not a child lost a friend or more during the transition (dummy variable). 
Table A-4: Effect of Peer Separation (with Quality) on Child's GPA

\section{Change in GPA}

(1)

One or More Peers Left

$-0.117^{* *}-0.075^{*}$

$(0.051) \quad(0.044)$

One or More Peers Left $\times$ GPA of Peers who Left

$0.049-0.004$

\begin{tabular}{lcc} 
& $(0.079)$ & $(0.071)$ \\
$\mathrm{N}$ & 1235 & 1235 \\
Controls & No & No \\
GPA (t-1) & No & Yes \\
\hline \hline
\end{tabular}

The table shows the heterogeneous disruptive effects of losing social ties in the transition from middle school to high school. The outcome is the change in a child's GPA during the transition from middle school to high school. We interact whether or not a child lost a friend with the baseline GPA of the peers who left. 
Table A-5: Effect of Peer Separation on Child's GPA (All grades)

\begin{tabular}{|c|c|c|c|c|c|c|c|c|c|}
\hline & \multicolumn{9}{|c|}{ Change in GPA } \\
\hline & (1) & (2) & (3) & (4) & (5) & (6) & (7) & (8) & (9) \\
\hline \multirow[t]{2}{*}{ One or More Peers Left $\times$ Grade $8(t-1)$} & $-0.123^{* *}$ & $-0.124^{* *}$ & $-0.131^{* *}$ & & & & & & \\
\hline & $(0.051)$ & $(0.051)$ & $(0.051)$ & & & & & & \\
\hline \multirow[t]{2}{*}{ Grade $8(t-1) \times N$. of Peers who Left } & & & & $-0.105^{* * *}$ & & $-0.106^{* * *}$ & & $-0.111^{* * *}$ & \\
\hline & & & & $(0.040)$ & & $(0.040)$ & & $(0.039)$ & \\
\hline \multirow[t]{2}{*}{1 Friend $\times$ Grade $8(t-1)$} & & & & & $-0.102^{*}$ & & $-0.103^{*}$ & & $-0.113^{* *}$ \\
\hline & & & & & $(0.054)$ & & $(0.054)$ & & $(0.056)$ \\
\hline \multirow[t]{2}{*}{2 Friends (or More) $\times$ Grade $8(\mathrm{t}-1)$} & & & & & $-0.218^{* *}$ & & $-0.218^{* *}$ & & $-0.219^{* *}$ \\
\hline & & & & & $(0.093)$ & & $(0.091)$ & & $(0.087)$ \\
\hline \multirow[t]{2}{*}{ One or More Peers Left $\times$ Grade $7(t-1)$} & 0.005 & 0.008 & -0.022 & & & & & & \\
\hline & $(0.058)$ & $(0.057)$ & $(0.054)$ & & & & & & \\
\hline \multirow[t]{2}{*}{ Grade $7(t-1) \times N$. of Peers who Left } & & & & 0.001 & & 0.004 & & -0.021 & \\
\hline & & & & $(0.052)$ & & $(0.052)$ & & $(0.049)$ & \\
\hline \multirow[t]{2}{*}{1 Friend $\times$ Grade $7(t-1)$} & & & & & 0.009 & & 0.012 & & -0.018 \\
\hline & & & & & $(0.052)$ & & $(0.052)$ & & $(0.049)$ \\
\hline \multirow[t]{2}{*}{2 Friends (or More) $\times$ Grade $7(t-1)$} & & & & & -0.015 & & -0.012 & & -0.049 \\
\hline & & & & & $(0.147)$ & & $(0.146)$ & & $(0.139)$ \\
\hline \multirow[t]{2}{*}{ One or More Peers Left $\times$ Grade $9(t-1)$} & -0.024 & -0.025 & -0.006 & & & & & & \\
\hline & $(0.055)$ & $(0.055)$ & $(0.047)$ & & & & & & \\
\hline \multirow[t]{2}{*}{ Grade $9(t-1) \times N$. of Peers who Left } & & & & -0.028 & & -0.030 & & -0.014 & \\
\hline & & & & $(0.042)$ & & $(0.042)$ & & $(0.036)$ & \\
\hline \multirow[t]{2}{*}{1 Friend $\times$ Grade $9(t-1)$} & & & & & -0.006 & & -0.008 & & 0.006 \\
\hline & & & & & $(0.057)$ & & $(0.056)$ & & $(0.050)$ \\
\hline \multirow[t]{2}{*}{2 Friends (or More) $\times$ Grade $9(\mathrm{t}-1)$} & & & & & -0.093 & & -0.095 & & -0.059 \\
\hline & & & & & $(0.087)$ & & $(0.087)$ & & $(0.080)$ \\
\hline \multirow[t]{2}{*}{ One or More Peers Left $\times$ Grade $10(t-1)$} & -0.033 & -0.034 & -0.004 & & & & & & \\
\hline & $(0.031)$ & $(0.031)$ & $(0.032)$ & & & & & & \\
\hline \multirow[t]{2}{*}{ Grade $10(t-1) \times N$. of Peers who Left } & & & & -0.033 & & -0.034 & & -0.013 & \\
\hline & & & & $(0.025)$ & & $(0.025)$ & & $(0.023)$ & \\
\hline \multirow[t]{2}{*}{1 Friend $\times$ Grade $10(t-1)$} & & & & & -0.019 & & -0.019 & & 0.008 \\
\hline & & & & & $(0.032)$ & & $(0.032)$ & & $(0.036)$ \\
\hline \multirow[t]{2}{*}{2 Friends (or More) $\times$ Grade $10(t-1)$} & & & & & -0.085 & & -0.091 & & -0.057 \\
\hline & & & & & $(0.063)$ & & $(0.063)$ & & $(0.054)$ \\
\hline \multirow[t]{2}{*}{ One or More Peers Left $\times$ Grade $11(t-1)$} & $0.087^{*}$ & $0.086^{*}$ & $0.107^{*}$ & & & & & & \\
\hline & $(0.045)$ & $(0.046)$ & $(0.058)$ & & & & & & \\
\hline \multirow[t]{2}{*}{ Grade $11(t-1) \times N$. of Peers who Left } & & & & 0.039 & & 0.038 & & $0.055^{*}$ & \\
\hline & & & & $(0.025)$ & & $(0.025)$ & & $(0.032)$ & \\
\hline \multirow[t]{2}{*}{1 Friend $\times$ Grade $11(t-1)$} & & & & & $0.120^{*}$ & & $0.119^{*}$ & & $0.128^{*}$ \\
\hline & & & & & $(0.061)$ & & $(0.061)$ & & $(0.069)$ \\
\hline \multirow[t]{2}{*}{2 Friends (or More) $\times$ Grade $11(t-1)$} & & & & & 0.029 & & 0.027 & & 0.065 \\
\hline & & & & & $(0.044)$ & & $(0.045)$ & & $(0.056)$ \\
\hline $\mathrm{N}$ & 7611 & 7611 & 7611 & 7611 & 7611 & 7611 & 7611 & 7611 & 7611 \\
\hline Controls & No & Yes & Yes & No & Yes & Yes & Yes & Yes & Yes \\
\hline School F.E. & No & No & Yes & No & No & No & No & Yes & Yes \\
\hline
\end{tabular}


Figure A-1: Simulated Effects of Covid on a Parenting Style: Authoritative Investments (Absent Time Constraints)

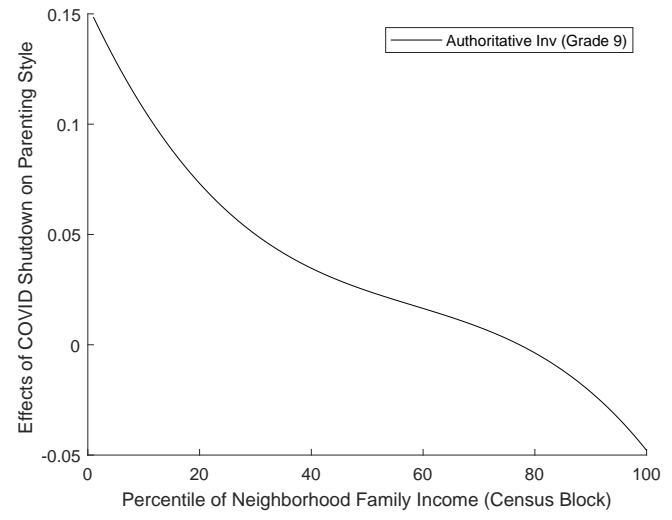

(a) Grade 9

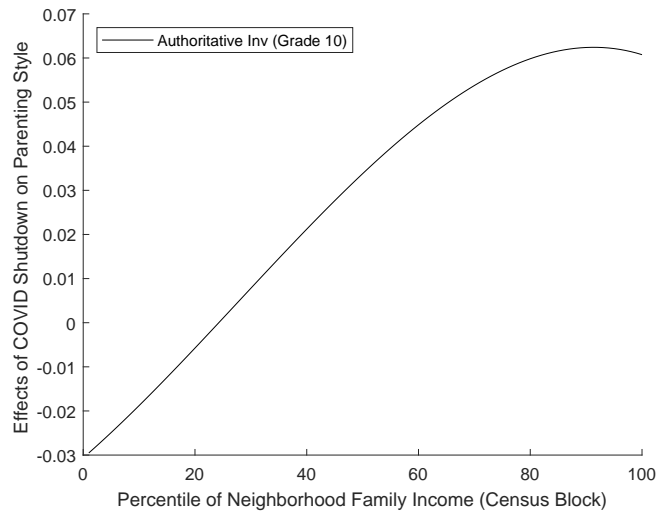

(b) Grade 10

The figure shows the effect of Covid on the parental investments by neighborhood income. The y-axis displays the change in parental investments after the Covid shock (relative to baseline). The $x$-axis represents the percentile of neighborhood income where children live. 